\title{
A systematic review of vaccine-induced thrombotic thrombocytopenia in individuals who received COVID-19 adenoviral-vector-based vaccines
}

\author{
Mostafa H. Elberry ${ }^{1}$. Hussien Ahmed H. Abdelgawad ${ }^{2,3,4}$. Aboalmagd Hamdallah ${ }^{5}$. Walid Shaban Abdella ${ }^{5}$. \\ Ahmed Sayed Ahmed ${ }^{6} \cdot$ Hazem S. Ghaith $^{7} \cdot$ Ahmed Negida $^{8,9,10}$ (D)
}

Accepted: 25 December 2021 / Published online: 14 February 2022

(c) The Author(s) 2022

\begin{abstract}
Reports of thrombotic response after receiving COVID-19 Adenoviral-Vector Based Vaccines raise concerns about vaccineinduced thrombotic thrombocytopenia (VITT); therefore, we conduct this systematic review to report susceptible demographics outcomes, commonalities, and prognosis of reporting cases. We identified published articles by searching PubMed, SCOPUS, and Web of Science from December 2020 till May 2021, with an updated search in September 2021. All case reports and case series reporting thrombotic response after receiving COVID-19 Adenoviral-Vector Based Vaccines were eligible for including. In addition, two authors independently extracted data and assessed the quality of the included studies. A total of 157 patients with thrombotic events after the ChAdOx1 nCoV-19 vaccine and 16 patients with thrombotic events after Ad26.COV2. S vaccine was included in our study. $72 \%$ of the ChAdOx1 nCoV-19 cases were females, while in Ad26.COV2.S subgroup, all reported patients were females. The commonest presentations were deep vein thrombosis 20 (12.7\%) and cerebral venous sinus thrombosis $18(11.5 \%)$ in the ChAdOx1 $\mathrm{nCoV}-19$ subgroup while cerebral venous sinus thrombosis 14 (87.5\%) and pulmonary embolism 2 (12.5\%) in the Ad26.COV2. S subgroup. In this study, we described the certain demographics associated with VITT and the clinical presentations of those cases in the ChAdOx $1 \mathrm{nCoV}-19$ and Ad26.COV2. S vaccines. Young individuals, particularly females, may be more susceptible to VITT, and future studies should seek to confirm this association. In addition, the clinical presentation of VITT commonly includes cerebral thrombi, pulmonary embolism, and deep venous thrombosis, but other presentations are also possible, highlighting the importance of clinical vigilance in recent vaccine recipients.
\end{abstract}

Keywords COVID-19 $\cdot$ SARS-CoV-2 $\cdot$ Vaccine $\cdot$ AstraZeneca $\cdot$ Johnson and Johnson $\cdot$ ChAdOx1 nCoV-19

Hussien Ahmed H. Abdelgawad

huabd1@morgan.edu; hussien.ahmed649@gmail.com

$\triangle$ Ahmed Negida

ahmed.said.negida@gmail.com

1 Virology and Immunology Unit, Cancer Biology Department, National Cancer Institute, Cairo University, Cairo, Egypt

2 Clinical Research Management Program, Edson College of Nursing and Health Innovation, Arizona State University, Phoenix, USA

3 Center for Urban Health Disparities Research and Innovation, Morgan State University, Baltimore, MD, USA
4 Department of Biology, Morgan State University, Baltimore, MD, USA

5 Faculty of Medicine Al-Azhar University, Damietta, Egypt

6 Faculty of Medicine, Ain Shams University, Cairo, Egypt

7 Faculty of Medicine Al-Azhar University, Cairo, Egypt

8 Department of Global Health and Social Medicine, Harvard Medical School, Boston, MA, USA

9 School of Pharmacy and Biomedical Sciences, University of Portsmouth, Portsmouth, UK

10 Faculty of Medicine, Zagazig University, Sharkia, Egypt 


\section{Highlights}

- Thrombotic risk increases in young females after receiving received COVID-19 adenoviral-vector-based vaccines.

- The most common clinical presentations of vaccineinduced thrombotic thrombocytopenia are cerebral thrombi, pulmonary embolism, and deep venous thrombosis.

- Longitudinal head to head studies are needed to confirm the association.

\section{Introduction}

The COVID-19 epidemic as a major public health problem has been associated with increased morbidity and mortality worldwide. The available antiviral drugs and other experimental drugs did not show any significant efficacy against the severe acute respiratory syndrome coronavirus-2 (SARSCoV-2) [1].

Vaccination against SARS-CoV-2 that minimizes both the rates of infection and serious complications is one of the most effective strategies to prevent and control the current COVID-19 pandemic [2-6]. New vaccines against SARS$\mathrm{CoV}-2$ have been produced at a rate unprecedented in medical history [7]. In addition, dozens of COVID-19 candidate vaccines have been registered in the clinical trial database (clinicaltrials.gov) [8].

Based on large-scale clinical trial results, the mRNA vaccine (BNT162b2) developed by Pfizer/BioNTech was the first vaccine to be granted FDA approval in December 2020 [4], and other vaccines soon followed in its footsteps following the publication of their trial results. Two vaccines approved by the European Medicines Agency are adenoviral vector-based vaccines (ChAdOx1 nCoV-19, COVID-19 Vaccine AstraZeneca [Vaxzevria] and Ad26.COV2. S, Covid-19 Vaccine Janssen). Although the efficacy and effectiveness of these multiple vaccines have been established, important differences as storage conditions, validity durations, mechanisms of action, number of doses required, and side-effects [9].

Following vaccination with Ad26.COV2. S or ChadOx1 nCoV-19, cases of thrombosis consistent with thrombocytopenia, known as vaccine-induced thrombotic Thrombocytopenia (VITT), have been identified. Many of these cases have been linked to autoantibodies against the platelet factor 4 (PF-4) antigen, which are similar to those observed in patients with autoimmune heparin-induced Thrombocytopenia (HIT) [10-13]. The first of these case reports, to our knowledge, was published on the 8th of April by D'Agostino et al. [14], with a slew of other reports following thereafter. In addition, events have also been reported for Ad26.COV2. $\mathrm{S}$ vaccine, with the earliest report being that of See et al. [11].

The importance of these complications is several-fold: first, from a medical perspective, it is important to understand as well as possible a potential complication of a vaccine that is going to be distributed on such a massive scale, both in terms of treatment and for risk-benefit calculations. Second, owing to the potential fatality of some of these complications and the media coverage they've received, they may contribute to a significant increase in vaccine hesitancy [15]. This is especially problematic as issues of hesitancy preceded the side-effect reports owing to a general distrust of the pharmaceutical establishment, and such side-effects are only likely to further exacerbate said distrust. Third, because of easier storage conditions, the $\mathrm{ChAdOx} 1 \mathrm{nCoV}-19$ vaccine is more likely to be consumed in developing countries than alternatives such as mRNA-based vaccines. To that extent, minimizing global disparities due to the COVID pandemic includes the supply of sufficient vaccines to nations in need and the minimization of any adverse effects thereof.

Therefore, this systematic review aims to summarize the reported cases of thrombosis and thrombocytopenia in patients receiving adenoviral vector-based COVID-19 vaccines to identify the susceptible demographics, outcomes, and commonalities in terms of predispositions across the reported cases. Second, reporting on the outcomes of the reported cases.

\section{Methods}

We followed the guidelines of the Preferred Reporting Items for Systematic Reviews and Meta-analysis (PRISMA statement) and the Meta-analysis of Observational Studies in Epidemiology (MOOSE statement) when conducting this systematic review [16].

\section{Literature search strategy}

We searched PubMed, SCOPUS, and Web of Science from December 2020 till May 2021, with an updated search on September 2021, for relevant articles reporting the thromboembolic events after Adenovirus vector-based vaccines using the following Keywords: "ChAdOx1 nCoV-19 vaccine", "AstraZeneca Vaccine" "Ad26.COV2. S", "Johnson \& Johnson Vaccine", "COVID-19", "SARS-CoV-2", "Thrombosis", and "Thrombocytopenia" as seen in Supplementary File 1. 


\section{Eligibility criteria and Study selection}

Studies achieving the following PIOS criteria were included:

Population: Reports of individuals who developed thrombosis and thrombocytopenia associated with ChAdOx1 nCoV-19 or Ad26.COV2. S vaccines administration Indicator (or risk factor): $\mathrm{ChAdOx} 1 \mathrm{nCoV}-19$ vaccine or Ad26.COV2. S administration

Outcome: Reports of individuals who developed postvaccination thrombosis and thrombocytopenia.

Study design: Articles that were described as case reports and case series

We excluded animal, laboratory, in vitro studies, conferences, reviews, and book chapters. Two authors independently screened the retrieved citations, and this was performed in two steps: title and abstract screening, followed by full-text screening. Finally, we examined the reference lists of included articles to identify additional studies. Any disagreements were resolved by discussion.

\section{Assessing the risk of bias}

Two reviewers independently assessed the quality of the eligible articles using the appropriate quality assessment tools, which depend on the study design of each of the included articles. For the case series, we used the NIH Quality Assessment Tool for case series [17], and the Joanna Briggs Institute (JBI) checklist to appraise the case reports [18]. The $\mathrm{NIH}$ criteria assess studies based on the following domains: clarity of objectives, clarity of study population and case definitions, whether the cases were consecutive and comparable, whether interventions were described clearly, the reliability and validity of outcome measurement, adequacy of follow-up length, statistical methodology, and whether results were well-described. The JBI checklist assesses the following: clarity of patient demographics, clinical history and presentation, diagnostic assessments, treatments, condition post-treatment, adverse events, and takeaway points.

\section{Data extraction}

We extracted the data from each included study using a pre-specified uniform data extraction sheet. The extracted data included the following domains: the number of patients included, demographic data on the country, age and sex, the type of vaccine received, clinical features including comorbidities, time to admission, and symptoms on admission, laboratory findings including coagulation parameters (PT/ aPTT), platelet count, hemoglobin, D-dimers, fibrinogen levels, antiplatelet factor 4 assays, the location of thrombotic events, management including the choice of medications (steroids, IVIG, heparin coagulation, non-heparin anticoagulants), and outcomes on recovery or death.

\section{Results}

\section{Literature Search}

A total of 1006 records were identified in the initial literature search and reference lists of included articles. Records were screened by titles and abstracts, and 971 articles were excluded. Thirty-five articles were retrieved for full-text evaluation. Twenty-six articles that met our criteria were included in this systematic [10-13, 19-40] (see PRISMA flow diagram, Fig. 1).

\section{Characteristics of cases among the included studies}

This systematic review included case report $(n=16)$, and case series $(n=10)$ described cases developing events of thrombosis and thrombocytopenia after administration of ChAdOx1 nCoV-19 vaccine $(n=157)$, or Ad26. COV2. $S$ vaccine $(n=16)$. Most cases $(72 \%$ and $100 \%$ in the ChAdOx1 and Ad26.COV2. S cohorts, respectively) were female. The overall age was relatively low (mean of 43.2 years in the ChAdOx1 cohort, 8 (50\%) patients were below 40 in the Ad26.COV2. S cohort). The average time from vaccination to admission was 10.5 and 15.9 days in the ChAdOx1 and Ad26.COV2. S cohorts, respectively. The summary of included studies is presented in Table 1, and a descriptive summary of included cases is presented in Table 2.

\section{Symptoms at Admission and Pre-existing conditions}

On admission, various symptoms were present in 49 patients (33 patients in ChAdOx1 nCoV-19 and 16 patients in Ad26. COV2. S), including headache, eye symptoms, fever, back pain, epigastric pain, and nausea/vomiting. In addition, our analysis identified numbers of comorbidities in 21 patients in the Chadox 1 cohort and two patients in the Ad26.COV2. S cohort as Meniere's disease, Hashimoto's thyroiditis, von Willebrand disease, hypertension, asthma, chronic neurologic disorders, and hypothyroidism as presented in Table 2 .

\section{Thromboembolic events}

In the 157 cases in the ChAdOx $1 \mathrm{nCoV}-19$ group, most of the patients presented with various Thromboembolic events such as cerebral venous sinus thrombosis $18(11.5 \%)$, cerebral venous thrombosis 15 (9.6\%), deep vein thrombosis 20 (12.7\%), and pulmonary embolism 16 (10.1\%). The 16 cases in the Ad26.COV2. S group presented with cerebral venous 
Fig. 1 Shows the PRISMA flow chart which summarizes the literature search, and included studies
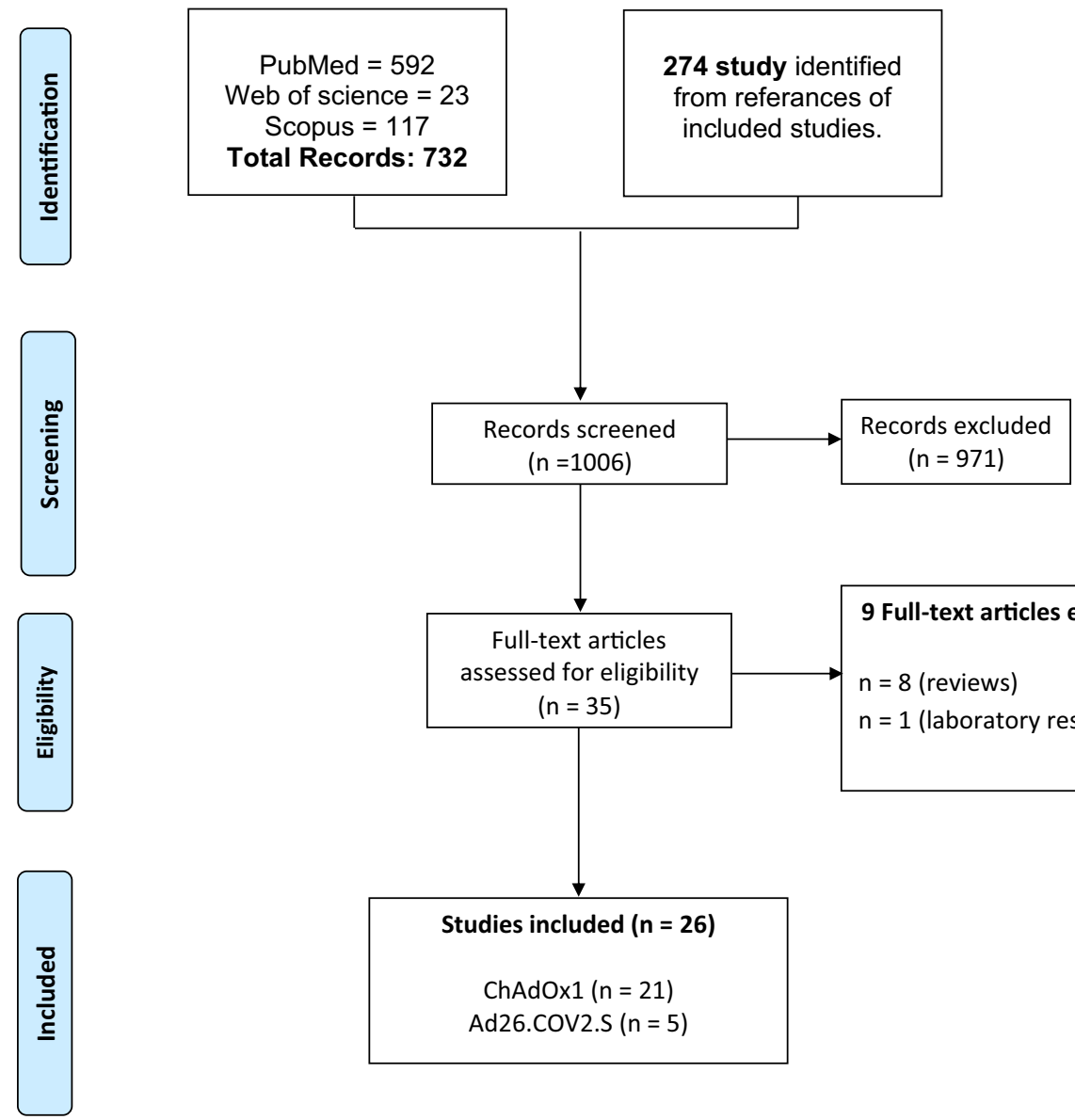

Studies included $(\mathbf{n}=\mathbf{2 6})$

ChAdOx1 $(n=21)$

Ad26.COV2.S $(n=5)$ sinus thrombosis 14 (87.5\%), cerebral venous thrombosis 1 (6.3\%), and pulmonary embolism 1 (6.3\%) (Tables 1 and 2).

\section{Laboratory finding}

The median level of platelet count was 33,500 cells $/ \mathrm{mm}^{3}$ (7000-334,000) in 62 patients received ChAdOx $1 \mathrm{nCoV}-$ 19 vaccine, and 20,000 cells $/ \mathrm{mm}^{3}(9000-127,000)$ in 16 patients received Ad26.COV2 vaccine. The D-dimer levels in the ChAdOx $1 \mathrm{nCoV}-19$ group were elevated in 52 patients (33.1\%) while in Ad26.COV2. S group, it was elevated in 15 patients (93.7\%). The antibodies against PF4 in the ChAdOx $1 \mathrm{nCoV}-19$ group were positive in 39 patients (24.8\%) while in Ad26.COV2. S group, it was positive in 13 patients $(81.2 \%)$. The median fibrinogen level was $1.2 \mathrm{~g} / \mathrm{liter}$ (0.4-5.7) in 62 patients who received the ChAdOx $1 \mathrm{nCoV}-$ 19 vaccine and 141 (59-332) in 16 patients who received Ad26.COV2 vaccine. The detailed description of all laboratory findings can be seen in Tables 1 and 2 .

\section{Treatment and Prognosis}

In the 145 cases in the ChAdOx $1 \mathrm{nCoV}-19$ group, 48 $(30.6 \%)$ patients reported receiving one or more thrombosis treatment such as heparin therapy in $20(41.6 \%)$, nonheparin anticoagulation in $8(16.7 \%)$, corticosteroids in 18 (37.5\%), and Intravenous immunoglobulin in 29 (60.4\%). In Ad26.COV2. S group, all 16 patients reported receiving one or more treatment such as heparin therapy in 7 (43.8\%), non-heparin anticoagulation in $2(12.5 \%)$, and corticosteroids in $8(50 \%)$.

In the ChAdOx $1 \mathrm{nCoV}-19$ group, about $21.7 \%$ on the patients $(n=34)$ had achieved a full recovery, $13.4 \%(n=21)$ were recovering, and $115.9 \%(\mathrm{n}=25)$ had died. While in Ad26.COV2. S group, about $28.5 \%$ on the patients $(n=4)$ had achieved a full recovery, $35.7 \%(n=5)$ were recovering, and $21.4 \%(n=3)$ had died. Of the 20 cases in the ChAdOx 1 $\mathrm{nCoV}-19$ group treated with heparin, eight patients reached full recovery, five patients were recovering, and six cases died. In patients treated with non-heparin anticoagulation, there were five cases of full recovery, one patient recovering, and no patient died. The prognostic and treatment details can be seen in Tables 1 and 2 .

In the ChAdOx $1 \mathrm{nCoV}$-19 group, 29 patients received IVIG, but only 8 patients reported prognoses with IVIG; five patients $(17.2 \%)$ had achieved a full recovery, one patient (3.4\%) was recovering, and two (6.9\%) had died. We did not 


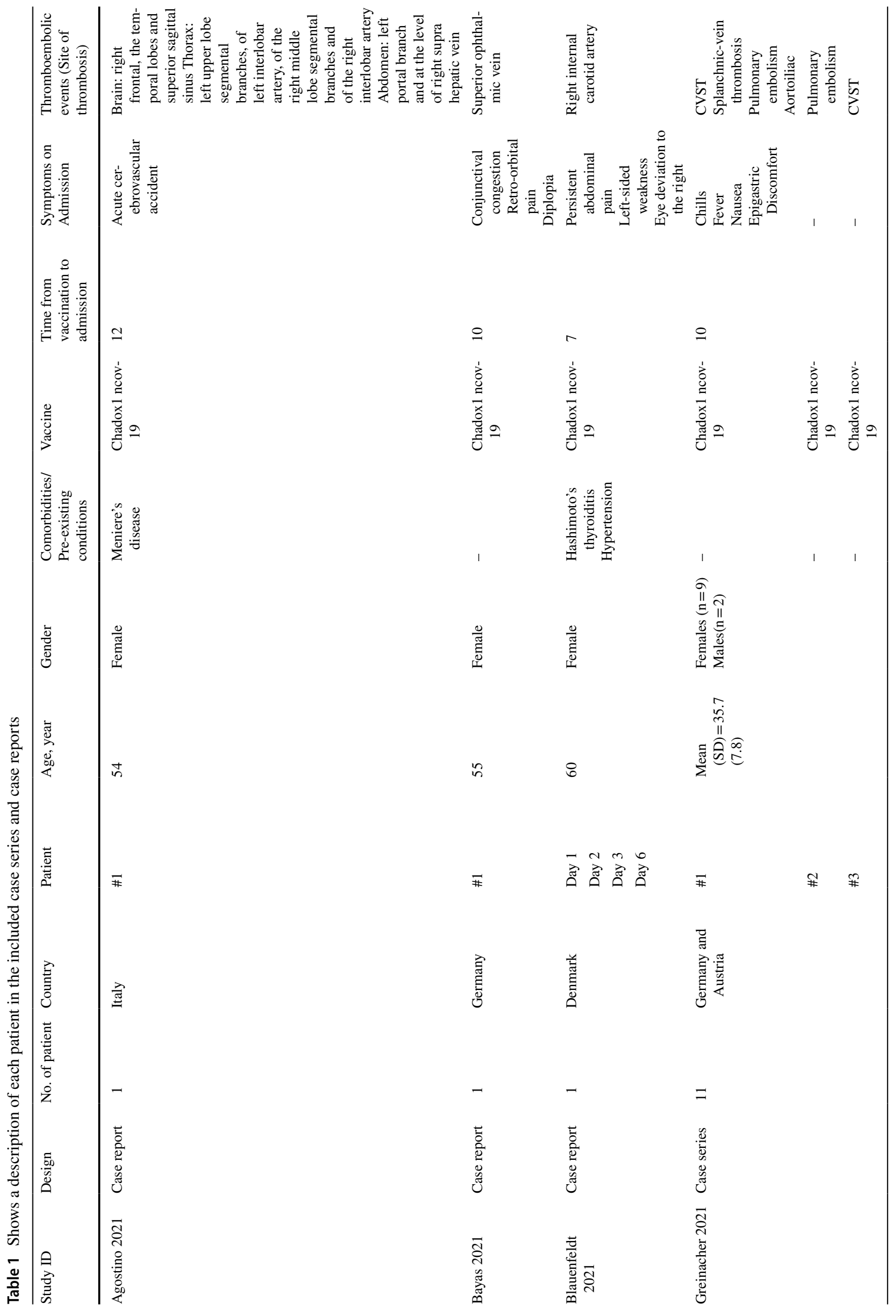


A systematic review of vaccine-induced thrombotic thrombocytopenia in individuals who received...

803

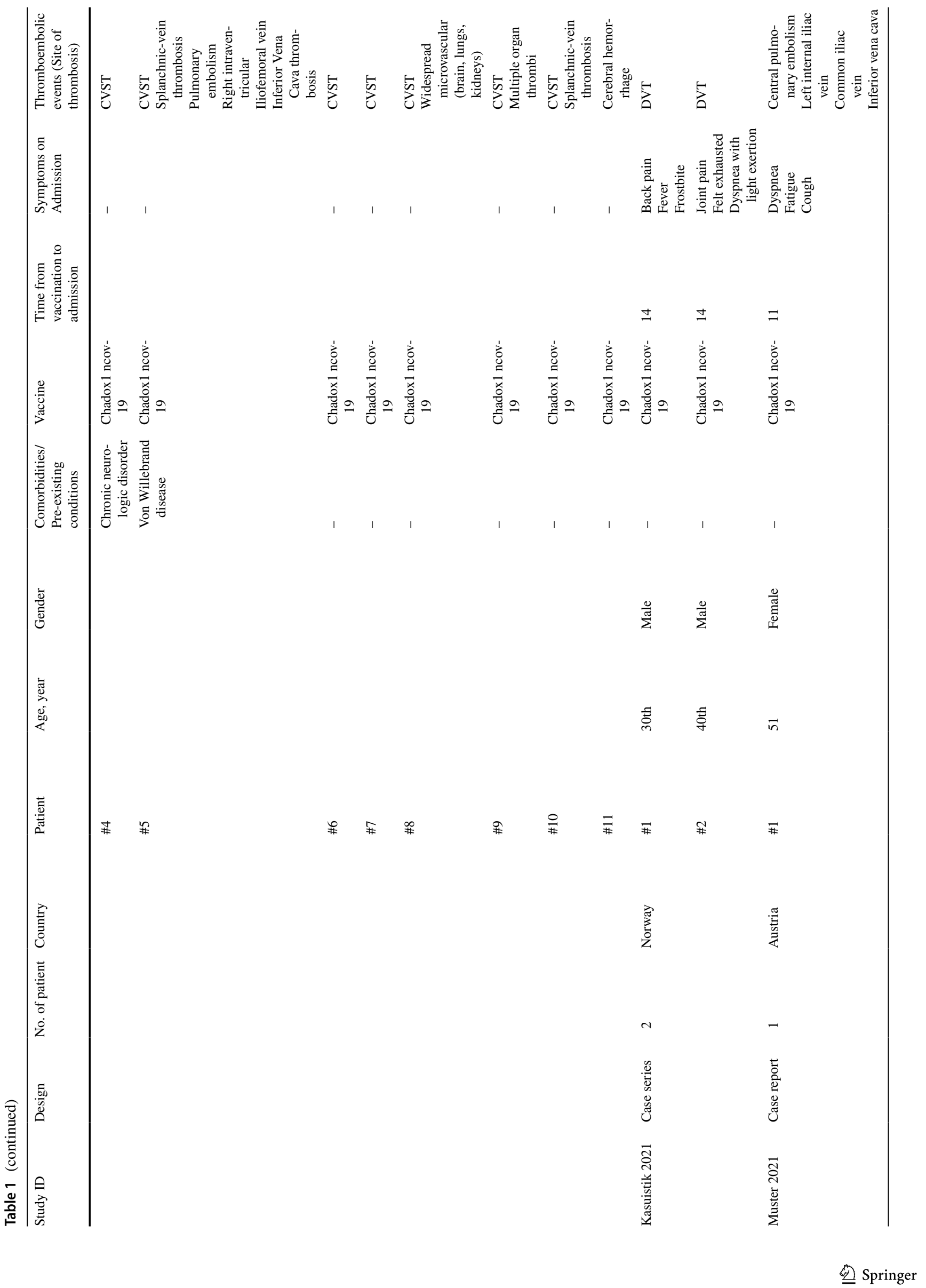




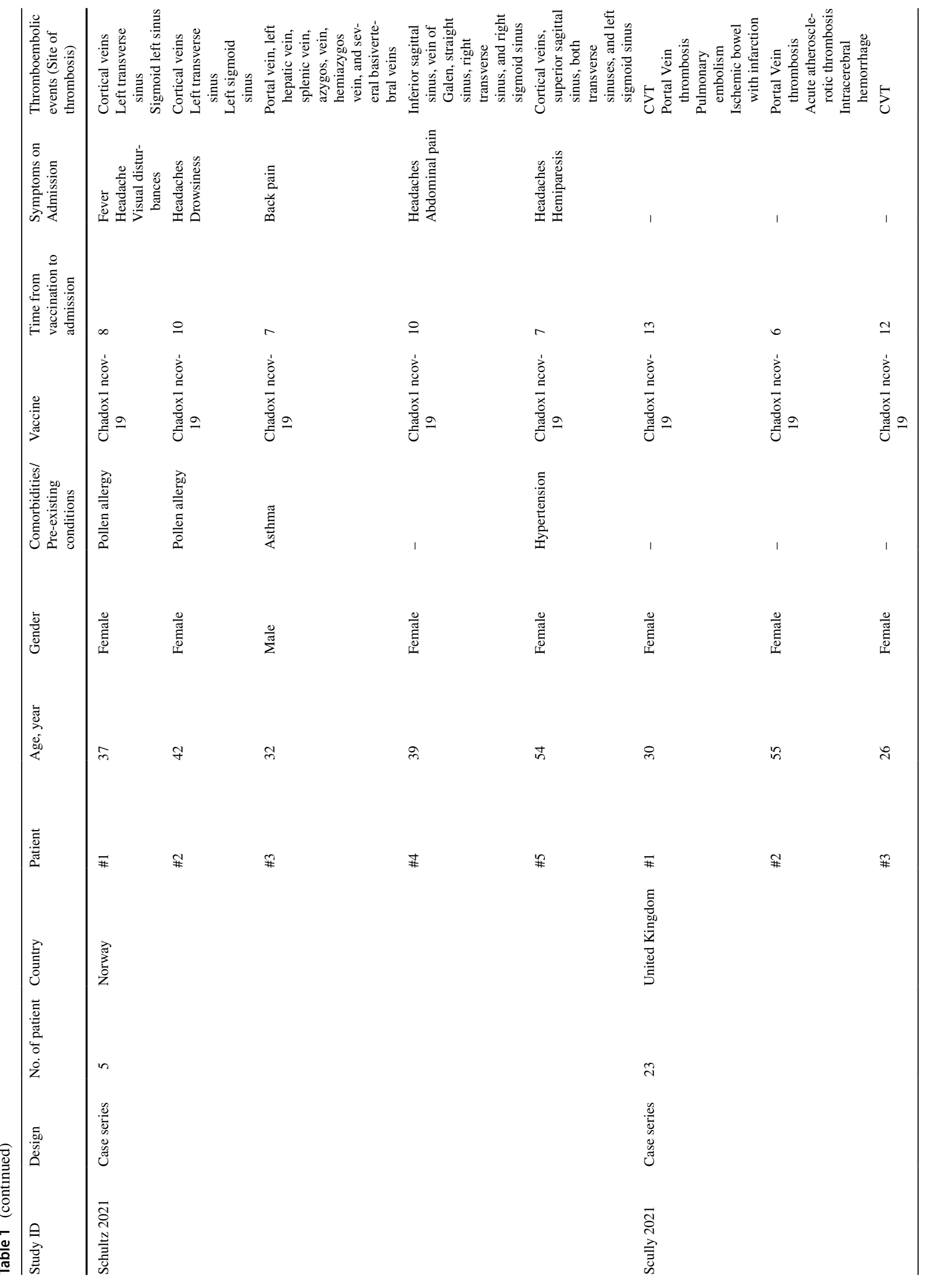




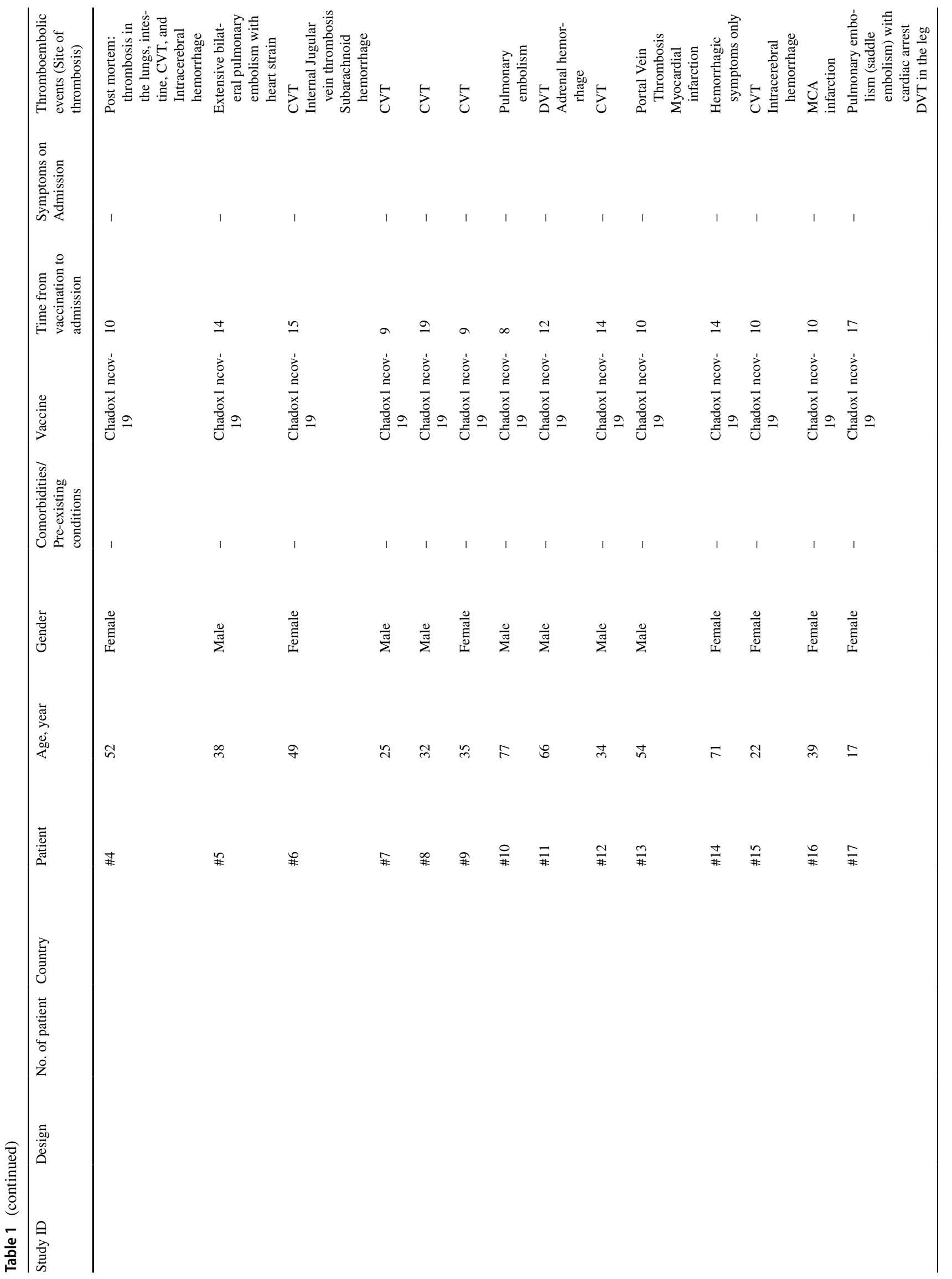




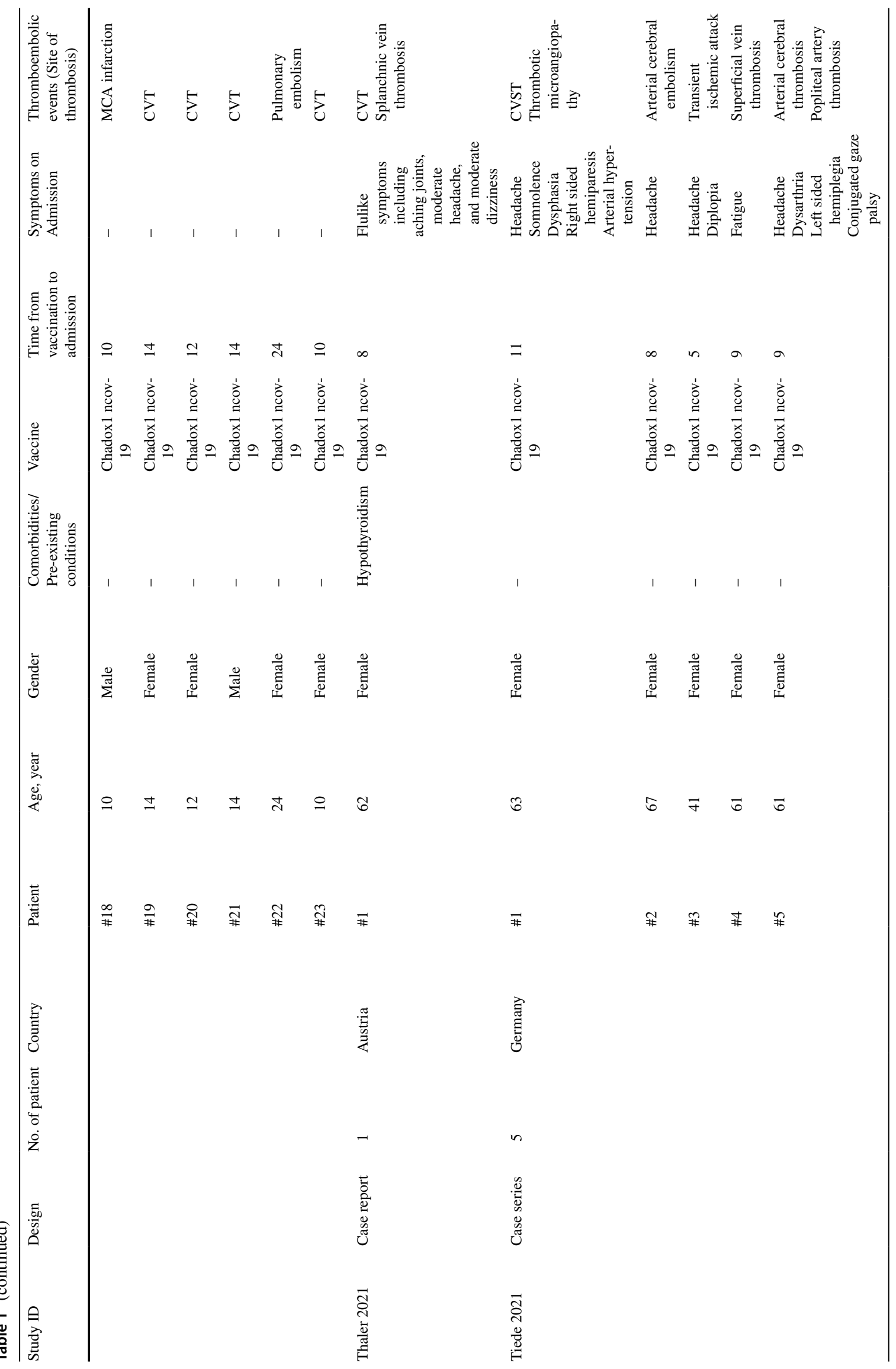




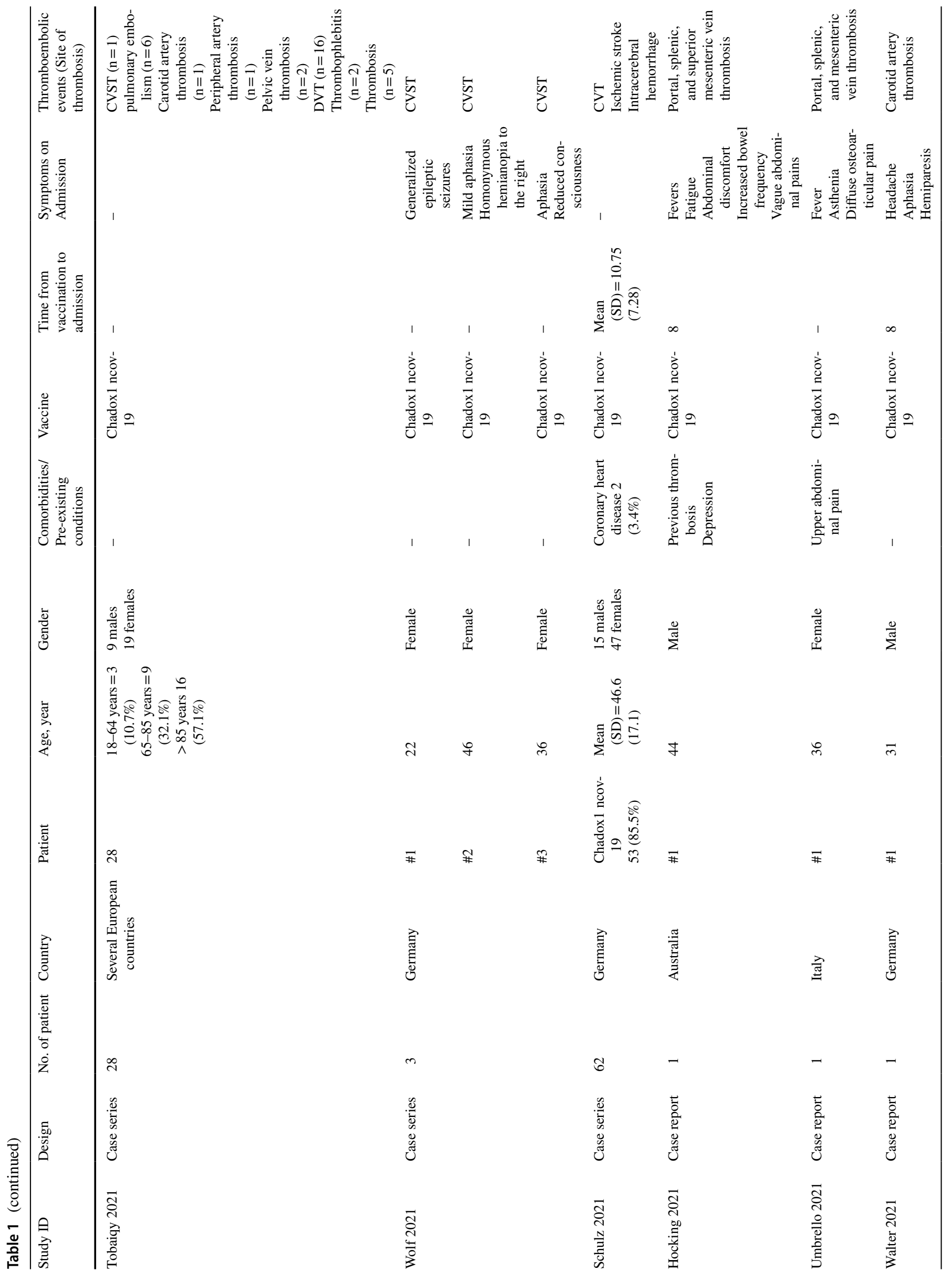




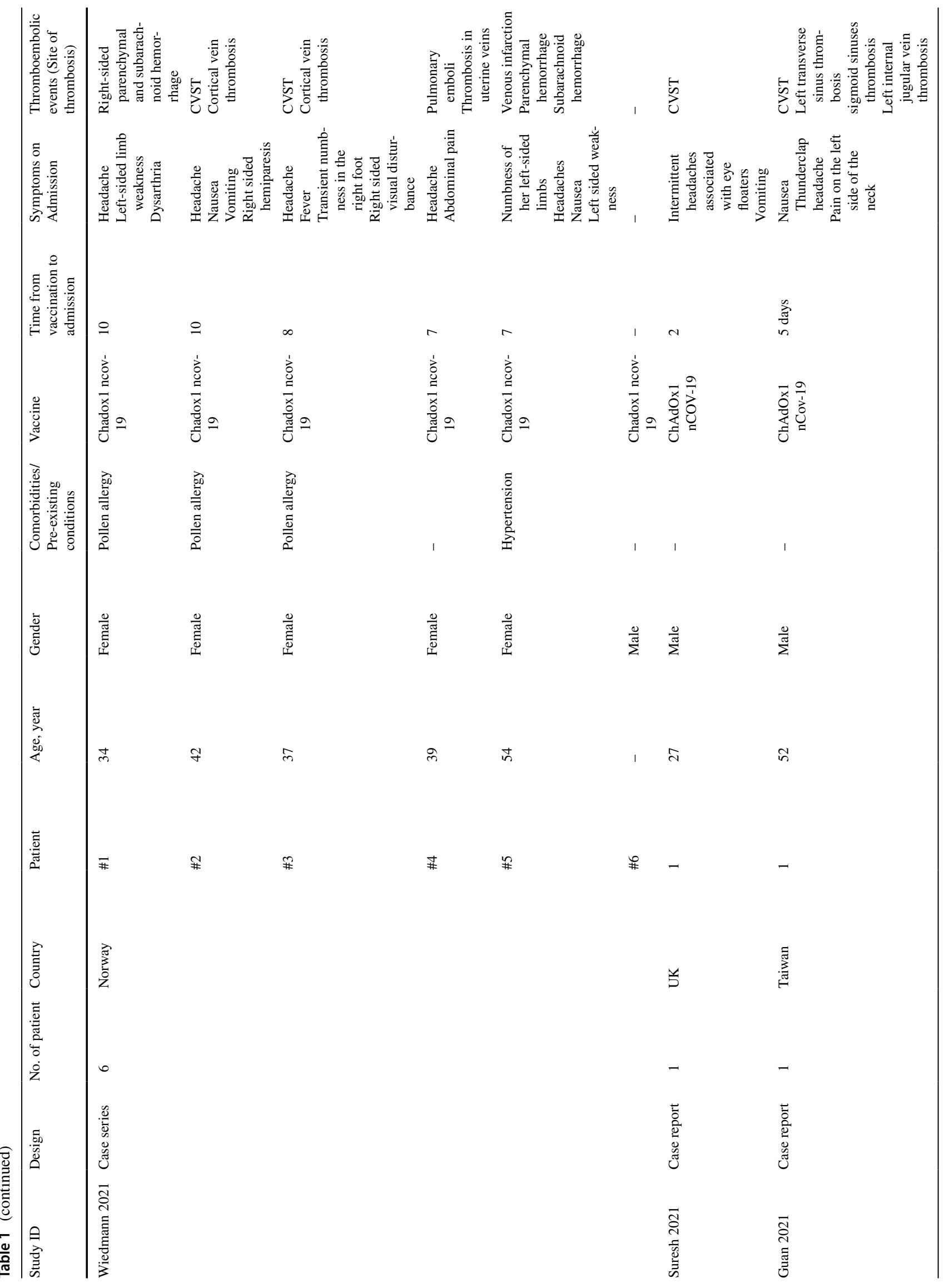




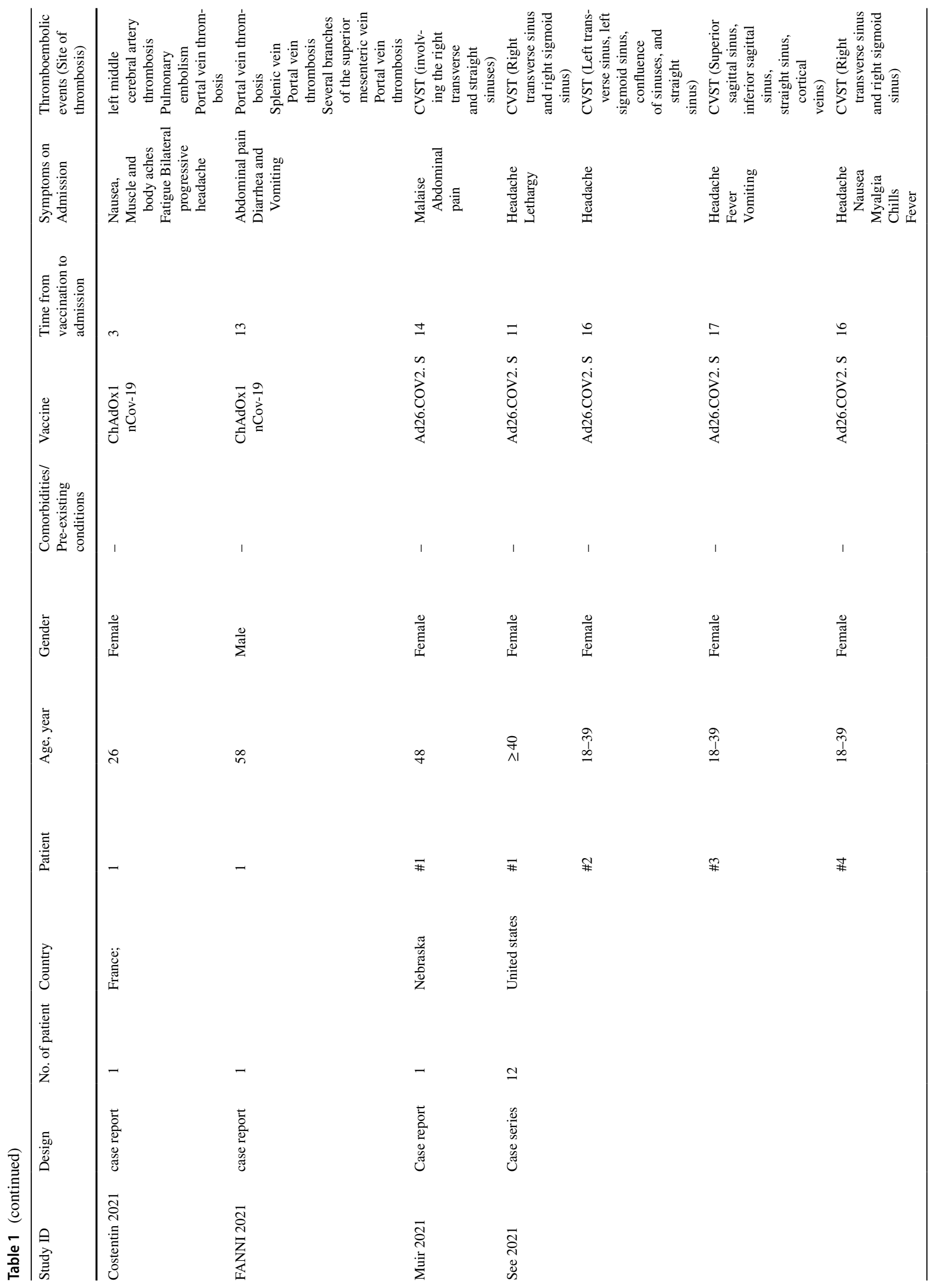




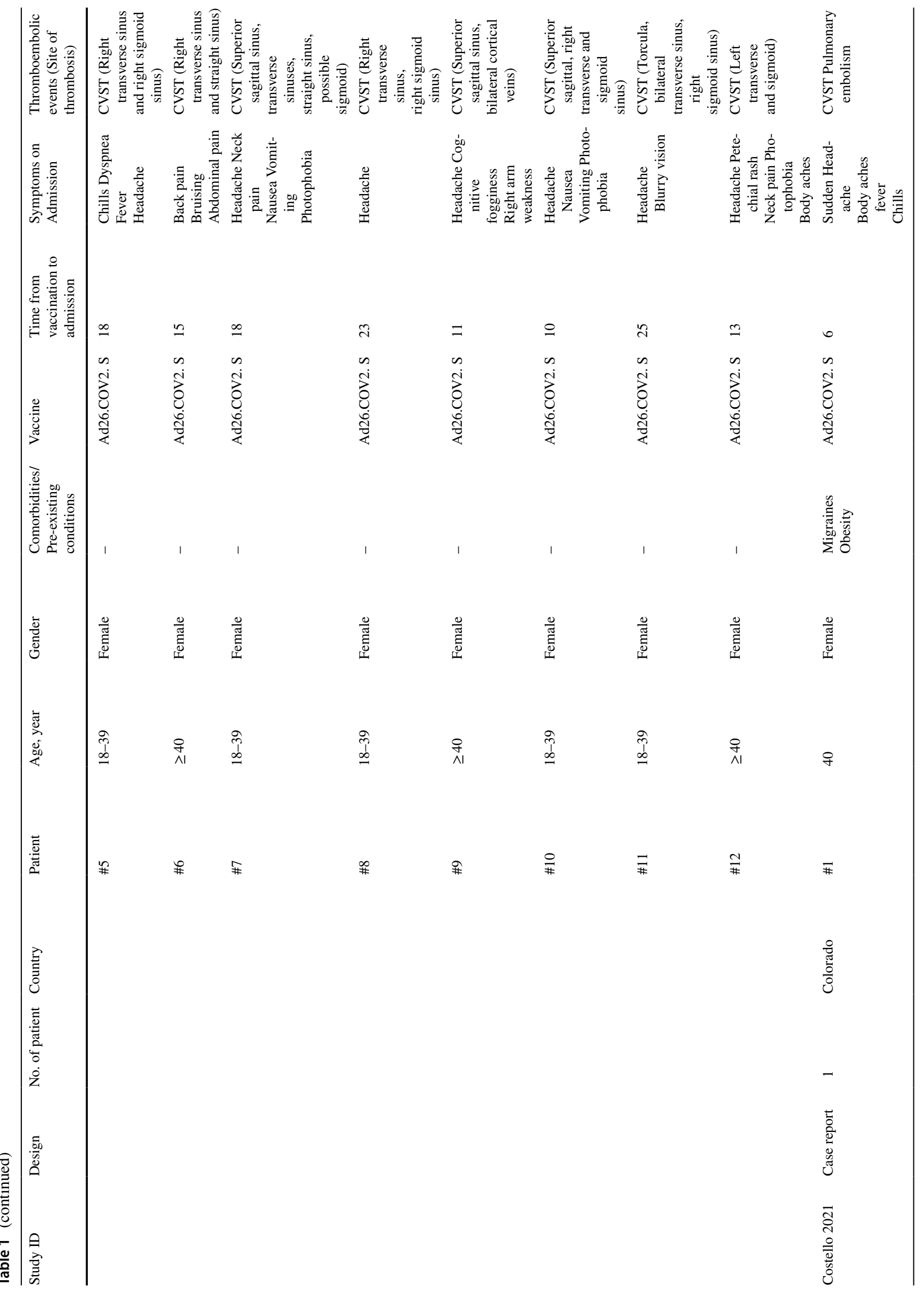




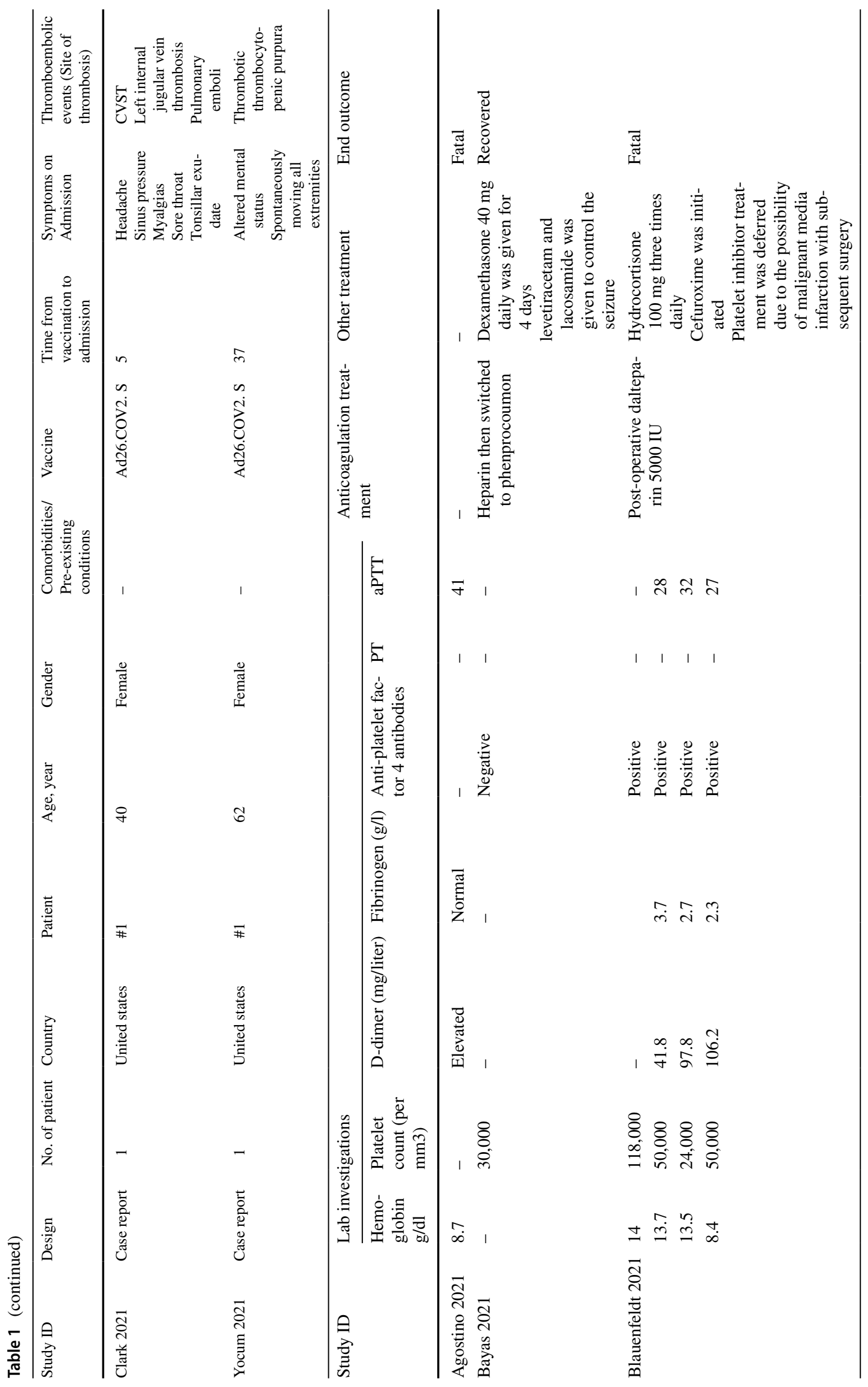




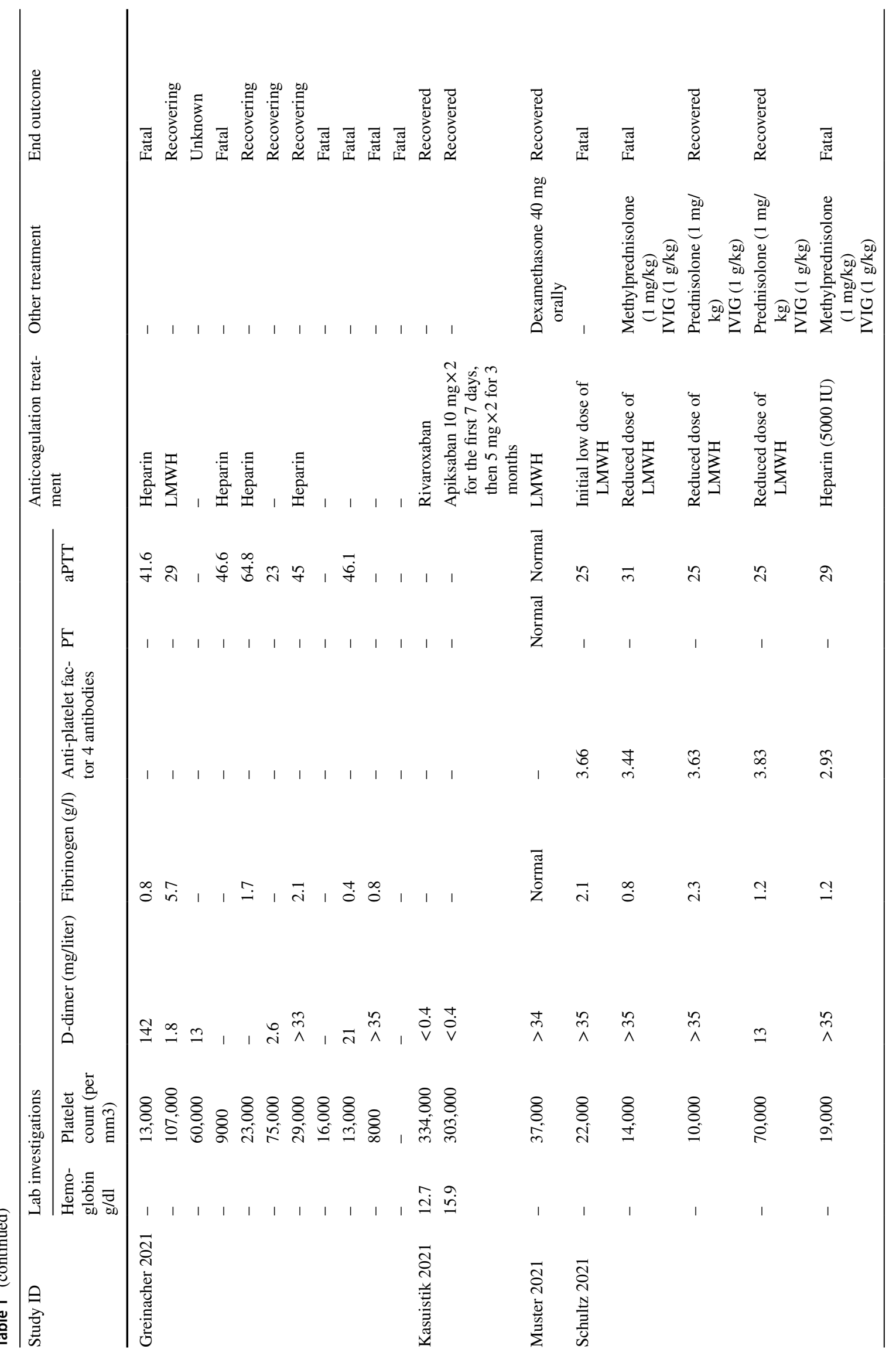




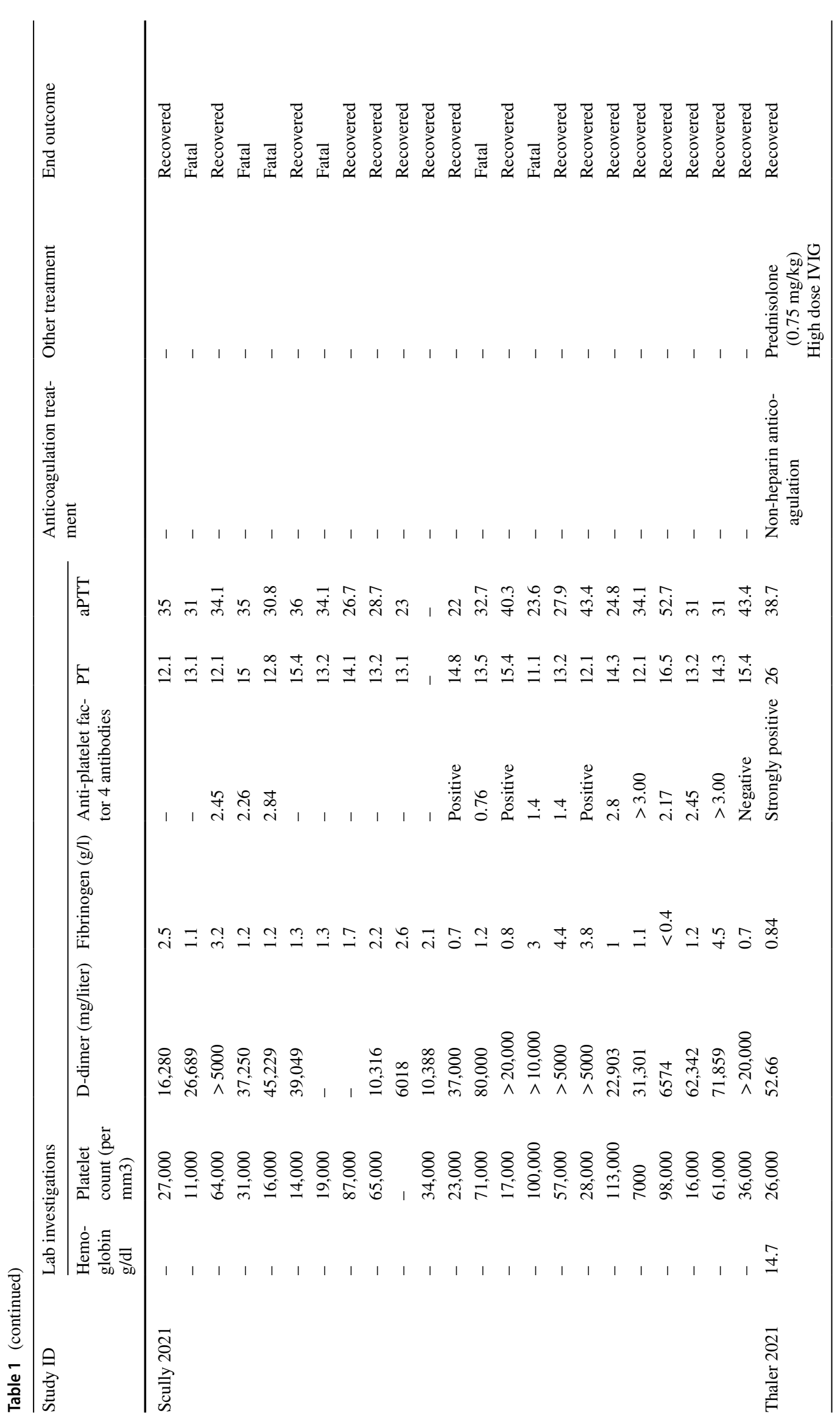




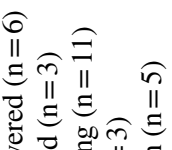

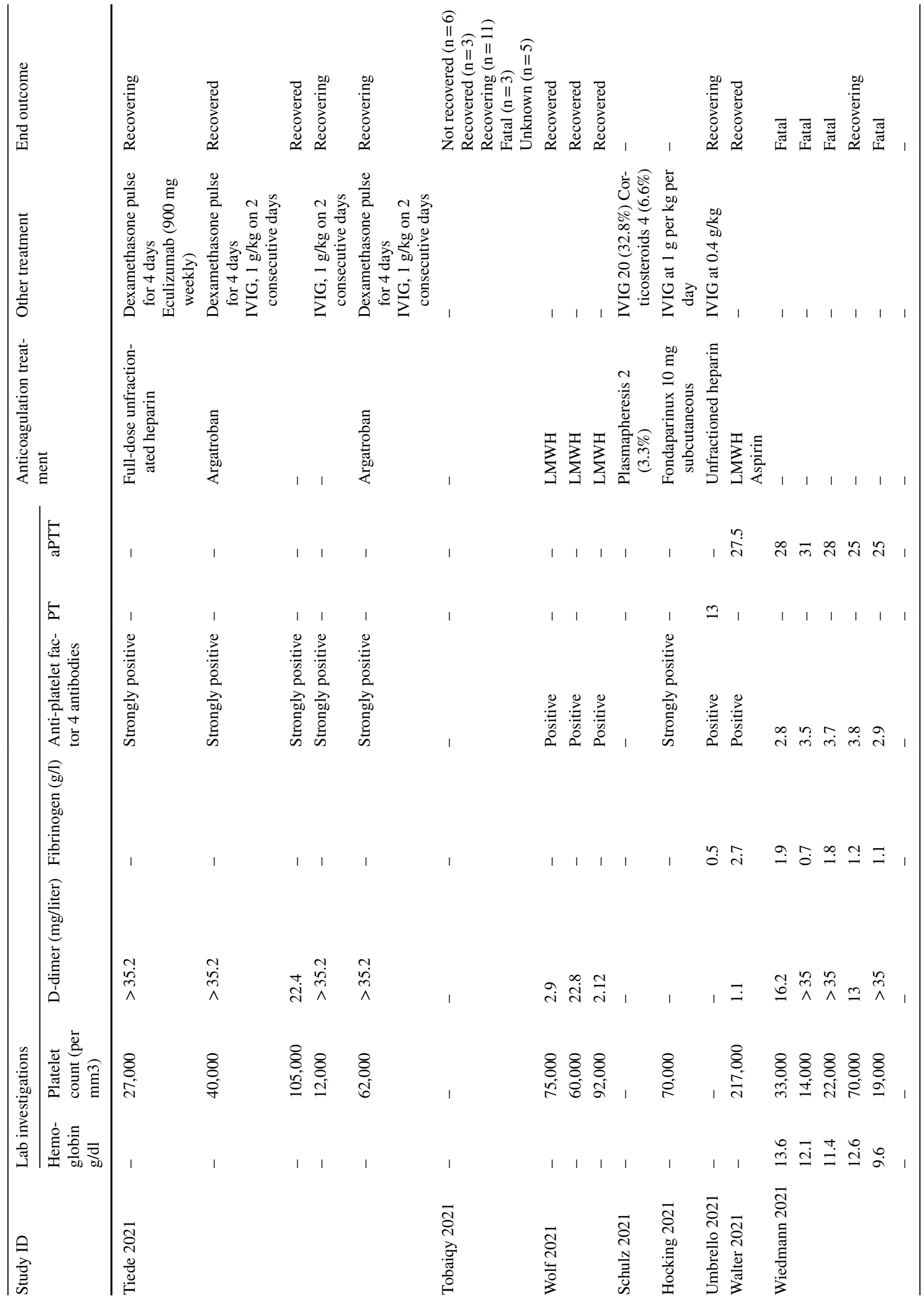




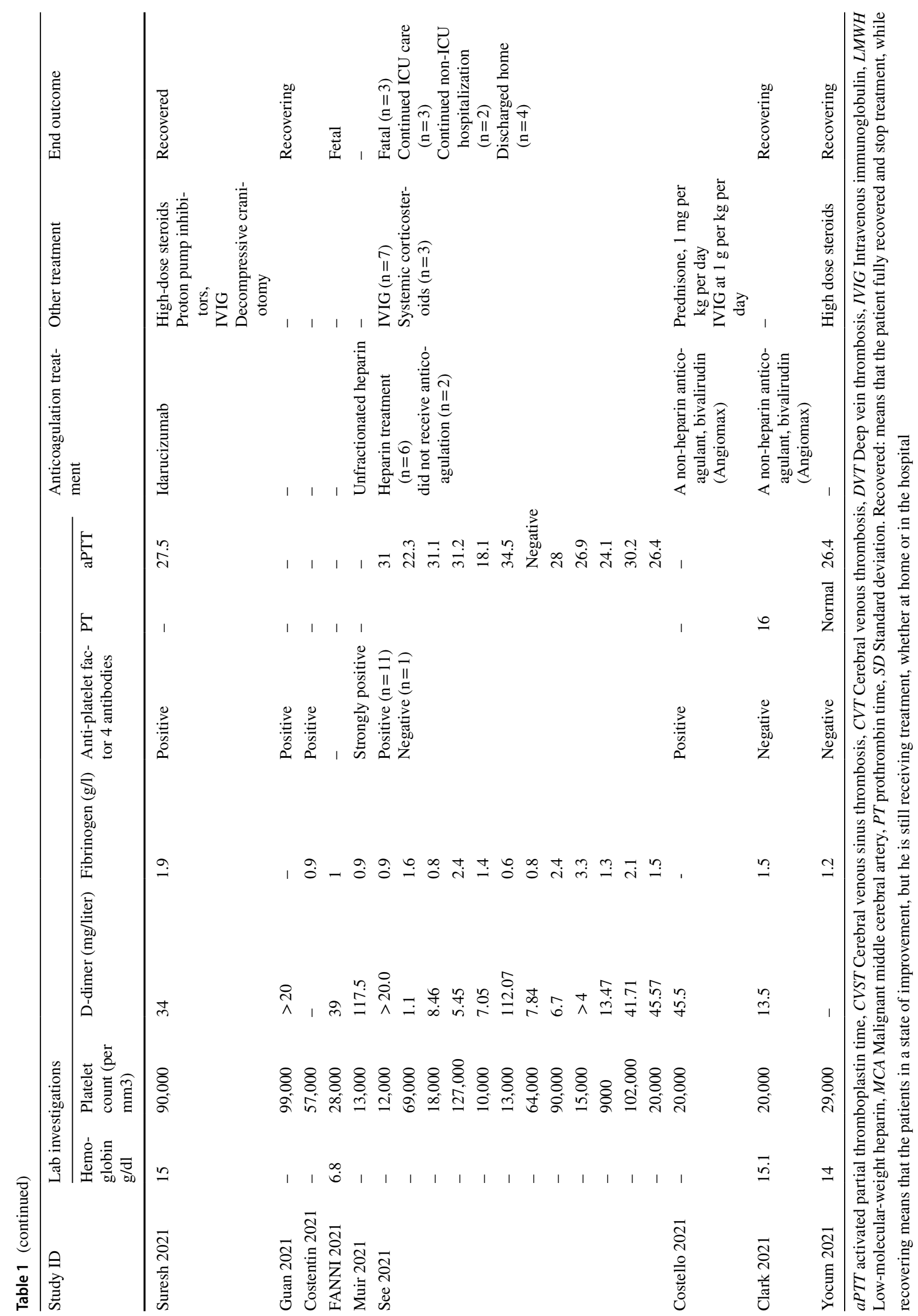


identify any published reports for IVIG withAd26.COV2. $S$ vaccine.

\section{Quality assessment}

Overall, the methodological quality of seven case reports was moderate to high quality according to the JBI Critical Appraisal Checklist for Case Reports [18]. According to NIH Quality Assessment Tool for Case Series Studies, the quality of the eight case series ranged from moderate to high quality [17]. The quality assessment of the included studies is shown in Fig. 2; the summary of the quality assessment of each study is shown in Supplementary S 1-2. The most concerning domains related to unclear statistical methods and unclear reporting on adverse events/conditions post-treatment.

\section{Discussion}

In this systematic review of the published reports of VITT, we identified a total of 159 published cases, 145 of which occurred with the ChAdOx1 nCoV-19 vaccine, and 14 of which occurred with the Ad26.COV2. S vaccine. The GamCOVID-Vac vaccine (recombinant adenovirus vector based on the human serotypes 3 and 26 adenovirus carrying the S-protein gene of the SARS-CoV-2) did not have any reports of VITT. The only mention of a thrombotic event with this vaccine was in a patient developing a DVT attributable to pre-existing comorbidities in one clinical trial [41].

Two important demographic features that stand out concerning these VITT events are age and sex distribution. The mean age for the events associated with the ChAdOx 1 nCoV-19 vaccine was 43.5 years, and most events were associated with the Ad26.COV2. S vaccine occurred in those below 40 years of age. This age distribution has important public health implications, particularly with the vaccine-hesitancy rates on rise in these population age groups. Individuals in these middle age groups usually experience a milder COVID-19 than the elderly [42]; therefore, they might fearfully choose to avoid these vaccinations. Whenever feasible, health policymakers and public health officials may consider providing alternative vaccines to those at the highest risk of VITT.

It is worth our notice that some individuals may be at a higher risk of COVID-induced thrombotic events, as cases of coagulopathy have been reported in younger individuals $[43,44]$. Nevertheless, the risk-benefit calculus is likely to vary depending on an individual's age, local infection rates, and comorbidities. Indeed, in the UK, those below the age of 30 have been offered alternative vaccination options due to similar concerns [45]. This is particularly important from a global health perspective in those developing countries, which tend to have younger populations, may be more affected by this issue.

An important positive aspect of our findings is that elderly patients, who are at higher risk of COVID-related complications [46] and most in need of vaccines, seemed less likely to suffer from VITT based on our data since most cases occurred in younger individuals.

In addition, there was a relative preponderance of females with VITT in this study (73\% in ChAdOx1 nCoV-19 vaccine, and all the cases in Ad26.COV2. S vaccine). Although there may be some concerns that the higher number of females with events is merely a reflection of more females than males getting vaccinated, studies do not suggest the discrepancies in vaccination rates, which are often in the 40 vs. $60 \%$-range [47], fully account for this difference. However, it is important to note that females are generally more likely to seek healthcare services than males [48], which may be an additional contributing factor.

Another issue is that the cases in our review had a relatively low number of comorbidities. However, our study design does not allow us to determine whether any of the comorbidities mentioned above is a risk factor for thrombotic events. Since healthy individuals are relatively less likely than individuals with several comorbidities to have COVID-19-related complications, they may be tempted to avoid these vaccines under the possibly erroneous assumption that they are less likely to die from COVID-19 than from a vaccine-associated thrombotic event.

Regarding the clinical presentation of these patients, the most common category of symptoms was neurological in nature, including headaches, seizures, hemiparesis, and ophthalmic symptoms. Nevertheless, it is important to note that various additional symptoms may be present, including fever, cough, epigastric pain, and fatigue. Therefore, the sensitivity of any set of symptoms may not be very high, although this would require confirmation in future studies.

These symptoms are distributed following the course of venous thrombi, most of which occur within the cerebral venous system. That said, it is important to note that thrombi may be detected in other locations, such as the lower limb veins (leading to pulmonary emboli) and the portal veins. These fewer common locations for thrombus formation may account for the less commonly presenting symptoms such as cough and abdominal pain.

The theorized mechanism behind VITT has been closely linked to that of heparin-induced thrombotic Thrombocytopenia (HIT). Supporting data for this hypothesis include the presence of anti-platelet factor 4 antibodies (anti-PF4) in both conditions [49]. These antibodies then bind to platelets, creating immune complexes and precipitating thrombotic events. In their study, Greinacher et al. [49] propose the following mechanism: following injection, vaccine components activate platelets, which release PF4. Vaccine components 
Table 2 Shows the overall descriptive summary of included cases

\begin{tabular}{|c|c|c|}
\hline & ChAdOx1 & Ad26.COV2. S \\
\hline Patient No. & 157 & 13 \\
\hline \multicolumn{3}{|l|}{ Gender } \\
\hline Male n $(\%)$ & $44(28 \%)$ & 0 \\
\hline Female n $(\%)$ & $113(72 \%)$ & $16(100 \%)$ \\
\hline Age years, mean (SD) & $\begin{array}{l}\text { mean }(\mathrm{SD})=43.2(16.7))[\mathrm{n}=129] \\
18-39(41 \text { patient }) \\
40-60(81 \text { patient }) \\
\geq 60(35 \text { patient })\end{array}$ & $\begin{array}{l}18-39 \text { (8 patients) } \\
\geq 40 \text { (8patients) }\end{array}$ \\
\hline \multicolumn{3}{|l|}{ Comorbidities/preexisting conditions } \\
\hline Reported Comorbidities n (\%)* & $21(13.4 \%)$ & $2(12.5 \%)$ \\
\hline Hypertension & $3(61.9 \%)$ & 0 \\
\hline Chronic neurologic disorder & $1(4.8 \%)$ & 0 \\
\hline Asthma & $1(4.8 \%)$ & 0 \\
\hline Pollen allergy & $5(23.8 \%)$ & 0 \\
\hline Meniere's disease & $1(4.8 \%)$ & 0 \\
\hline Hypothyroidism & $1(4.8 \%)$ & 0 \\
\hline Hashimoto's thyroiditis & $1(4.8 \%)$ & 0 \\
\hline von Willebrand disease & $1(4.8 \%)$ & 0 \\
\hline Coronary heart disease & $2(9.5 \%)$ & \\
\hline Migraines & 0 & $1(50 \%)$ \\
\hline Obesity & 0 & $1(50 \%)$ \\
\hline Other & $5(23.8 \%)$ & \\
\hline Not reported Comorbidities n (\%) & $136(86.6 \%)$ & $14(87.5 \%)$ \\
\hline Time from vaccination to admission days, mean (SD) & $10.5(5.8)[n=126]$ & $15.9(7.8)$ \\
\hline \multicolumn{3}{|l|}{ Symptoms on Admission n (\%) } \\
\hline Reported symptom n (\%)** & $33(21 \%)$ & $16(100 \%)$ \\
\hline Headache & $18(54.5 \%)$ & $13(81.3 \%)$ \\
\hline Eye symptoms & $9(27.3 \%)$ & $5(31.3 \%)$ \\
\hline Fever and Chills & $7(21.2 \%)$ & $7(43.8 \%)$ \\
\hline Back pain & $2(6 \%)$ & $1(6.3 \%)$ \\
\hline Fatigue & $4(12.1 \%)$ & 0 \\
\hline Joint pain & $3(9 \%)$ & 0 \\
\hline Cough & $1(3 \%)$ & 0 \\
\hline Frostbite & $1(3 \%)$ & 0 \\
\hline Nausea/Vomiting & $8(24.2 \%)$ & $6(37.5 \%)$ \\
\hline Hemiparesis & $4(12.1 \%)$ & 0 \\
\hline Dyspnea & $2(6 \%)$ & 0 \\
\hline Abdominal pain & $7(21.2 \%)$ & $2(12.5 \%)$ \\
\hline Aphasia, dysphasia, or dysarthria & $6(18.1 \%)$ & 0 \\
\hline Reduced consciousness & $2(6 \%)$ & $1(6.3 \%)$ \\
\hline Dizziness & $3(9 \%)$ & 0 \\
\hline Left sided hemiplegia & $1(3 \%)$ & 0 \\
\hline Arterial hypertension & $1(3 \%)$ & 0 \\
\hline Generalized epileptic seizures & $1(3 \%)$ & 0 \\
\hline Acute cerebrovascular accident & $1(3 \%)$ & 0 \\
\hline Lethargy/weakness/body aches & $7(21.2 \%)$ & $8(50 \%)$ \\
\hline Not reported symptoms & $124(79 \%)$ & 0 \\
\hline \multicolumn{3}{|l|}{ Thromboembolic events $\mathrm{n}(\%)^{* * *}$} \\
\hline Cerebral venous sinus thrombosis & $18(11.5 \%)$ & $14(87.5 \%)$ \\
\hline Cerebral venous thrombosis & $15(9.6 \%)$ & $1(6.3 \%)$ \\
\hline
\end{tabular}


Table 2 (continued)

\begin{tabular}{|c|c|c|}
\hline & ChAdOx 1 & Ad26.COV2. S \\
\hline Deep vein thrombosis & $20(12.7 \%)$ & - \\
\hline Pulmonary embolism & $16(10.1 \%)$ & $2(12.5 \%)$ \\
\hline Cortical veins & $3(1.9 \%)$ & - \\
\hline Portal Vein thrombosis & $6(3.8 \%)$ & - \\
\hline Carotid artery thrombosis & $3(1.9 \%)$ & - \\
\hline Splanchnic-vein thrombosis & $4(2.5 \%)$ & - \\
\hline Cerebral hemorrhage & $9(5.7 \%)$ & - \\
\hline Malignant middle cerebral artery (MCA) infarction & $2(1.3 \%)$ & - \\
\hline Inferior vena cava & $2(1.3 \%)$ & - \\
\hline Other & $70(44.6 \%)$ & $1(6.3 \%)$ \\
\hline \multicolumn{3}{|l|}{ Laboratory finding } \\
\hline Hemoglobin g/dl mean (SD) & $12.1(2.7)[n=12]$ & $14.5(0.8)[n=2]$ \\
\hline Platelet count cell per mm3 median (Range) & $33,500(7000-334,000)[n=62]$ & $20,000(9000-127,000)[n=16]$ \\
\hline D-dimer mg/l n (\%) & $\begin{array}{l}\text { Elevated } 52(33.1 \%) \\
\text { Not reported } 103(65.6 \%) \\
\text { Normal } 2(1.3 \%)\end{array}$ & $\begin{array}{l}\text { Elevated } 15(93.7 \%) \\
\text { Not reported } 1(6.3 \%)\end{array}$ \\
\hline D-dimer mg/l median (Range) & $26(0.4-142)[\mathrm{n}=53]$ & $13.5(1.1-117.5)[n=15]$ \\
\hline Fibrinogen (g/liter) median (Range) & $1.2(0.4-5.7)[\mathrm{n}=46]$ & $141(59-332)[n=15]$ \\
\hline Antibodies to Platelet Factor 4 n (\%) & $\begin{array}{l}\text { Positive } 39(24.8 \%) \\
\text { Negative } 2(1.3 \%) \\
\text { Not reported } 116(73.9 \%)\end{array}$ & $\begin{array}{l}\text { Positive } 13(81.2 \%) \\
\text { Negative } 3(18.8 \%)\end{array}$ \\
\hline Pt mean (SD) & $14.1(2.9)[\mathrm{n}=24]$ & - \\
\hline APTT mean (SD) & $33(9)[n=43]$ & $27.5(18.1-34.5)[\mathrm{n}=12]$ \\
\hline \multicolumn{3}{|l|}{ Treatment n $(\%) * * * *$} \\
\hline Reported treatments & $48(30.6 \%)$ & $16(100 \%)$ \\
\hline Heparin therapy & $20(41.6 \%)$ & $7(43.8 \%)$ \\
\hline Non-heparin anticoagulation & $8(16.7 \%)$ & $2(12.5 \%)$ \\
\hline Corticosteroids & $18(37.5 \%)$ & $5(31.3 \%)$ \\
\hline Intravenous immunoglobulin & $29(60.4 \%)$ & $8(50 \%)$ \\
\hline Not reported any treatment & $109(69.4 \%)$ & 0 \\
\hline \multicolumn{3}{|l|}{ End outcome n $(\%)$} \\
\hline Recovered & $34(21.7 \%)$ & $4(25 \%)$ \\
\hline Recovering & $21(13.4 \%)$ & $7(43.8 \%)$ \\
\hline Not recovered & $6(3.8 \%)$ & - \\
\hline Fatal & $25(15.9 \%)$ & $3(18.8 \%)$ \\
\hline Unknown & $71(45.2 \%)$ & $2(12.5 \%)$ \\
\hline \multicolumn{3}{|l|}{ Heparin therapy } \\
\hline Fatal & $6 / 20(30 \%)$ & - \\
\hline Recovered & $8 / 20(40 \%)$ & - \\
\hline Recovering & $5 / 20(25 \%)$ & - \\
\hline \multicolumn{3}{|l|}{ Non-heparin anticoagulation } \\
\hline Fatal & $0 / 8$ & - \\
\hline Recovered & $5 / 8(62.5 \%)$ & - \\
\hline Recovering & $1 / 8(12.5 \%)$ & - \\
\hline \multicolumn{3}{|l|}{ Corticosteroids } \\
\hline Fatal & $3 / 18(16.7 \%)$ & - \\
\hline Recovered & $8 / 18(44.4 \%)$ & - \\
\hline Recovering & $3 / 18(16.7 \%)$ & - \\
\hline \multicolumn{3}{|l|}{ IVIG } \\
\hline Fatal & $2 / 29(6.9 \%)$ & - \\
\hline
\end{tabular}


Table 2 (continued)

ChAdOx 1

Ad26.COV2. S

Recovered

$5 / 29(17.2 \%)$

Recovering

$1 / 29(3.4 \%)$

$a P T T$ activated partial thromboplastin time, $P T$ prothrombin time, $S D$ Standard deviation

$(*)$ : any patient might have one or more comorbidities, $(* *)$ : any patient might have one or more symptoms, $(* * *)$ : any patient might have one or more Thromboembolic events, $(* * * *)$ : any patient might receive one or more treatments

then bind to PF4, creating an immunogenic substance that is attacked by circulating IgG. Consequently, this forms a PF4/ IgG complex that can bind to the surface of platelets and activate them, resulting in a prothrombotic state. Notably, previous data on mice models did show thrombocytopenia as a transient adverse effect following recombinant adenovirusvectors [50].

However, our study points out one clinical difference between VITT and HIT. Unlike HIT, where DVT is usually the predominant thrombotic manifestation [51], our study shows cerebral thrombi to be more common overall, although $13.8 \%$ of patients had a DVT. Nevertheless, we find similarities with HIT as well. The average time from vaccination to admission amongst our studies was 10.9 and 15.2 days with the ChAdOx1 nCoV-19 and Ad26.COV2.S vaccines, respectively, which approximately corresponds to the temporal pattern of HIT, are typically quoted as occurring after 5 to 14 days post-exposure to heparin [52, 53]. Our findings were relatively close to previous studies; in a cohort study of 170 patients who developed VITT after receiving the $\mathrm{ChAdOx} 1 \mathrm{nCoV}-19$ vaccine, $97 \%$ of patients presented to the hospital with symptoms with 5th to 30th day with an average of 13.5 days from vaccination [54]. A systematic review that included data of 41 patients reported average durations from vaccination to admission of 8.9 and 10.3 days for the ChAdOx1 nCoV-19 and Ad26.COV2.S vaccines respectively [55].

Also in accordance with the clinical picture of HIT, where bleeding is very rare, is the absence of bleeding reports amongst our included reports [51]. This is despite the thrombocytopenic state common to both conditions. Importantly, the median platelet count in our study was 34,000 in the ChAdOx1 nCov-19 cohort, which points to a more vigorous platelet-depleting process than HIT, where platelets usually remain above 50,000 [56].

In our review, neither PT nor PTT was markedly prolonged, and $\mathrm{Hb}$ was not significantly decreased. In contrast, D-dimers seemed to be a relatively more sensitive marker amongst the included patients. Among those with anti-PF4 measured, most had positive titers, which corresponds with the findings mentioned above by Greinacher et al. [49].
Generally, ELISA anti-PF4 assays are recommended over other measurement modalities [39], as they may have higher sensitivity. Nevertheless, even anti-PF4 may not be $100 \%$ sensitive, as there was one negative anti-PF4 ELISA measurement in our study.

Since VITT is a relatively novel phenomenon, there are currently no robust evidence-based treatments with proven efficacy; however, given the similarities to HIT, similar treatment paradigms have been advocated [53, 57, 58]. Namely, the use of IVIG and direct anticoagulants such as argatroban or bivalirudin has been suggested in the acute phase, whereas the use of heparin products has been discouraged [57]. Further management would include eventual transition to an oral anticoagulant, preferably a DOAC rather than a vitamin-K-based regimen [53]. However, in our sample, $12.4 \%$ of patients received heparin products. The similarities to HIT in terms of pathophysiology caution that the use of heparin products may be unadvisable. IVIG and steroids were also utilized in some patients (6.2 and 9.7\% respectively in the ChAdOx1 nCov-19 cohort). After IVIG, five patients $(17.2 \%)$ had achieved a full recovery, one patient $(3.4 \%)$ was recovering, and two $(6.9 \%)$ had died. IVIG is recommended to improve VITT cases as IVIG inhibits the hypercoagulability process and increases platelet count, which in turn reduces the severity of VITT [59, 60]. The American Heart Association recommended IVIG $1 \mathrm{~g} / \mathrm{kg}$ for 2 days after testing positive for antibodies against PF4 [55]. To the best of our knowledge, there is no current evidence to support the use of steroids in HIT, with one observational study reporting an adverse association [61]. Generally speaking, platelet transfusions are advised against [57]; however, the American Association of Hematology currently states that platelet transfusions may be used if the condition is refractory to other modes of treatment and life-threatening bleeding is occurring [62]. Nevertheless, further studies are needed to understand whether treatments typically used in HIT patients can be safely and effectively extrapolated to VITT, as the evidence base for this entity is lacking.

Regarding the outcomes of patients with VITT, many patients in our study had recovered or were recovering; however, there was a relatively high case-fatality rate (13.8 and 
Fig. 2 Shows the risk of bias summary for each included study: A Risk of bias summary of included Case series. B Risk of bias summary of included Case reports

21.4\% in the ChAdOx1 nCov-19 and Ad26.COV2. S groups, respectively). This is likely an overestimate of the fatality rate as the cases most likely to be reported in the literature are ones on the severe end of the spectrum.

There are several important limitations of our study: First, as with any other review of the literature, there may be the concern of publication bias, as not all cases of VITT are equally likely to be published. Second, the available literature may have included the subset of patients with the most severe presentations of VITT, as milder cases may have been less likely to seek medical care; therefore, we cannot readily generalize the representativeness of our results across all possible cases of VITT. Third, though comorbidities were uncommon in our study population, our study design does not allow us to definitively establish an association (or lack thereof) between VITT and underlying comorbidities. Fourth, some included studies did not report all lab measurements, which may limit the accuracy of our findings.

Finally, the take-home message from this study for clinicians is that: (1) VITT might occur in young individuals and particularly females, (2) the typical presentation of VITT might include cerebral thrombi and other heterogeneous events, therefore, clinical experience is important for detection and early management of VITT in the vaccinated individuals, and (3) for individuals who are at higher risk of VITT, alternative SARS-CoV-2 vaccines should be provided whenever possible (Fig. 3). For future research, we recommend further large long-term longitudinal studies of the individuals who received ChAdOx1 nCov-19 and Ad26. COV2. $S$ vaccines with the aim of identifying the magnitude and risk factors of VITT in the different age groups. Such information will be important to inform health policy makers to guide their decisions about population vaccination choices.

In conclusion, in this study, we described the certain demographics associated with VITT and the clinical presentations of those cases in the ChAdOx $1 \mathrm{nCoV}-19$ and Ad26.COV2. S vaccines. Young individuals, particularly females, may be more susceptible to VITT, and future studies should seek to confirm this association. In addition, the clinical presentation of VITT commonly includes cerebral thrombi, pulmonary embolism, and deep venous thrombosis, but other presentations are also possible, highlighting the importance of clinical vigilance in recent vaccine recipients. Finally, the coagulation profile does not seem to be markedly altered in patients with VITT, with D-dimers and anti-PF4 likely being the most sensitive.
(A) Risk of bias summary of included case series. *

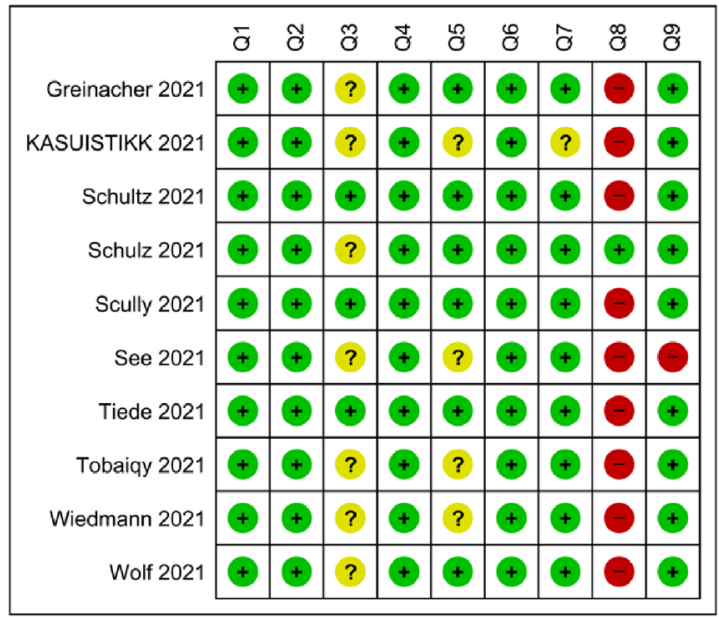

(B) Risk of bias summary of included case reports. \#

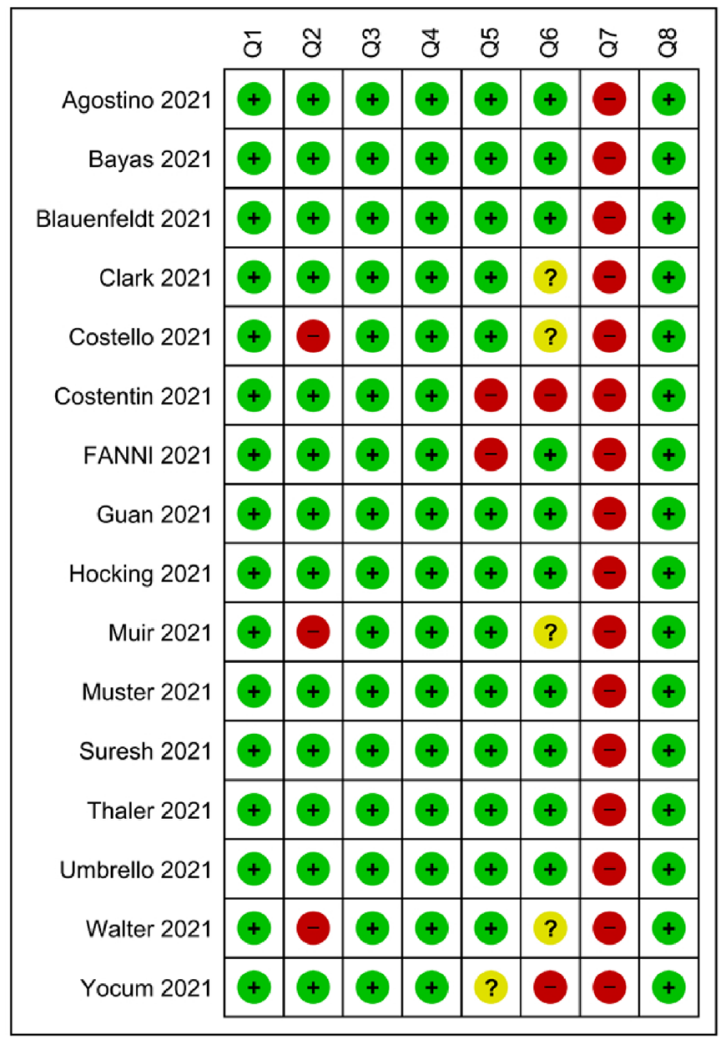

* Q1: Was the study question or objective clearly stated? Q2: Was the study population clearly and fully described, including a case definition? Q3: Were the cases consecutive? Q4: Were the subjects comparable? Q5: Was the intervention clearly described? Q6: Were the outcome measures clearly defined, valid, reliable, and implemented consistently across all study participants? Q7: Was the length of follow-up adequate? Q8: Were the statistical methods well-described? Q9: Were the results well-described?

\# Q1: Were patient's demographic characteristics clearly described? Q2: Was the patient's history clearly described and presented as a timeline? Q3: Was the current clinical condition of the patient on presentation clearly described? Q4: Were diagnostic tests or assessment methods and the results clearly described? Q5: Was the intervention(s) or treatment procedure(s) clearly described? Q6: Was the post-intervention clinical condition clearly described? Q7: Were adverse events (harms) or unanticipated events identified and described? Q8: Does the case eport provide takeaway lessons? 


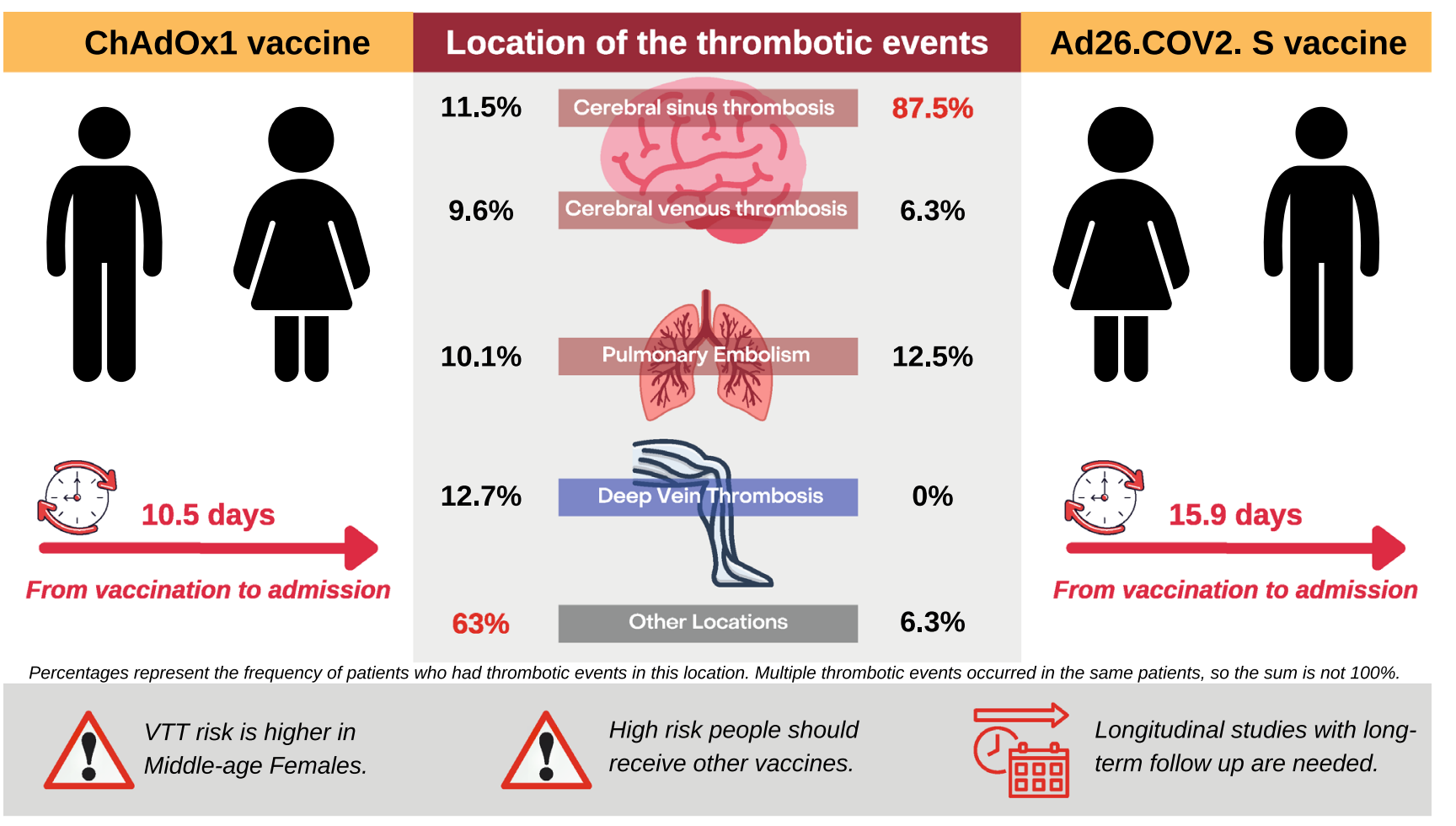

Fig. 3 The take home message for clinicians

Supplementary Information The online version contains supplementary material available at https://doi.org/10.1007/s11239-021-02626-w.

\section{Acknowledgements None}

Funding None to declare; this work is not funded by any third party.

\section{Declarations}

Conflict of interest None to declare; all authors report no disclosures.

Open Access This article is licensed under a Creative Commons Attribution 4.0 International License, which permits use, sharing, adaptation, distribution and reproduction in any medium or format, as long as you give appropriate credit to the original author(s) and the source, provide a link to the Creative Commons licence, and indicate if changes were made. The images or other third party material in this article are included in the article's Creative Commons licence, unless indicated otherwise in a credit line to the material. If material is not included in the article's Creative Commons licence and your intended use is not permitted by statutory regulation or exceeds the permitted use, you will need to obtain permission directly from the copyright holder. To view a copy of this licence, visit http://creativecommons.org/licenses/by/4.0/.

\section{References}

1. Pardo J, Shukla AM, Chamarthi G, Gupte A (2020) The journey of remdesivir: from Ebola to COVID-19. Drugs Context 9:1-9. https://doi.org/10.7573/dic.2020-4-14
2. Ahmed $\mathrm{H}$ et al (2020) A clinical review of COVID-19; pathogenesis, diagnosis, and management. Curr Pharm Des. https://doi.org/ $10.2174 / 1381612826666201222162509$

3. Voysey M et al (2021) Safety and efficacy of the ChAdOx1 nCoV19 vaccine (AZD1222) against SARS-CoV-2: an interim analysis of four randomised controlled trials in Brazil, South Africa, and the UK. Lancet 397(10269):99-111. https://doi.org/10.1016/ S0140-6736(20)32661-1

4. Polack FP et al (2020) Safety and efficacy of the BNT162b2 mRNA covid-19 vaccine. N Engl J Med 383(27):2603-2615. https://doi.org/10.1056/nejmoa2034577

5. Baden LR et al (2021) Efficacy and safety of the mRNA-1273 SARS-CoV-2 vaccine. N Engl J Med 384(5):403-416. https://doi. org/10.1056/nejmoa2035389

6. Sadoff $\mathrm{J}$ et al (2021) Interim results of a phase 1-2a trial of Ad26. COV2.S covid-19 vaccine. N Engl J Med. https://doi.org/10.1056/ nejmoa2034201

7. Li Y-D, Chi W-Y, Su J-H, Ferrall L, Hung C-F, Wu T-C (2020) Coronavirus vaccine development: from SARS and MERS to COVID-19. J Biomed Sci 27(1):104. https://doi.org/10.1186/ s12929-020-00695-2

8. Sumirtanurdin R, Barliana MI (2021) Coronavirus disease 2019 vaccine development: an overview. Viral Immunol 34(3):134-144. https://doi.org/10.1089/vim.2020.0119

9. Sharun K, Singh R, Dhama K (2021) Oxford-AstraZeneca COVID-19 vaccine (AZD1222) is ideal for resource-constrained low- and middle-income countries. Ann Med Surg 65:21-24. https://doi.org/10.1016/j.amsu.2021.102264

10. Scully $\mathrm{M}$ et al (2021) Pathologic antibodies to platelet factor 4 after ChAdOx1 nCoV-19 vaccination. N Engl J Med. https://doi. org/10.1056/NEJMoa2105385

11. See I et al (2021) US case reports of cerebral venous sinus thrombosis with thrombocytopenia after Ad26.COV2.S vaccination, 
March 2 to April 21, 2021. JAMA 30329:1-9. https://doi.org/10. 1001/jama.2021.7517

12. Muir K-L, Kallam A, Koepsell SA, Gundabolu K (2021) Thrombotic thrombocytopenia after Ad26.COV2.S Vaccination. N Eng1 J Med 384(20):1964-1965. https://doi.org/10.1056/nejmc21058 69

13. Schultz NH et al (2021) Thrombosis and thrombocytopenia after ChAdOx1 nCoV-19 vaccination. N Engl J Med. https://doi.org/ 10.1056/nejmoa2104882

14. D'Agostino V et al (2021) A rare case of cerebral venous thrombosis and disseminated intravascular coagulation temporally associated to the COVID-19 vaccine administration. J Pers Med 11(4):285. https://doi.org/10.3390/jpm11040285

15. Kaplan RM, Milstein A (2021) Influence of a COVID-19 vaccine's effectiveness and safety profile on vaccination acceptance. Proc Natl Acad Sci USA. https://doi.org/10.1073/pnas.20217 26118

16. Moher D et al (2009) Preferred reporting items for systematic reviews and meta-analyses: the PRISMA statement. J Chinese Integr Med 7(9):889-896. https://doi.org/10.3736/jcim20090918

17. Study Quality Assessment Tools I NHLBI, NIH. Available at https://www.nhlbi.nih.gov/health-topics/study-quality-asses sment-tools. Accessed on $31 \mathrm{Jul} 2020$

18. The Joanna Briggs Institute Critical Appraisal tools for use in JBI Systematic Reviews, 2017. [Online]. Available at http://joann abriggs.org/research/critical-appraisal-tools.htmlwww.joannabrig gs.org. Accessed on May 05, 2021

19. Umbrello $\mathrm{M}$ et al (2021) Successful treatment of acute splenoporto-mesenteric vein thrombosis after ChAdOx $1 \mathrm{nCoV}-19$ vaccine. A case report. J Crit Care 65:72-75. https://doi.org/10. 1016/j.jcrc.2021.05.021

20. Walter U et al (2021) Adenovirus-vectored COVID-19 vaccineinduced immune thrombosis of carotid artery: a case report. Neurology. https://doi.org/10.1212/wnl.0000000000012576

21. Wiedmann $\mathrm{M}$ et al (2021) Vaccine induced immune thrombotic thrombocytopenia causing a severe form of cerebral venous thrombosis with high fatality rate: a case series. Front Neurol 12:1-7. https://doi.org/10.3389/fneur.2021.721146

22. Wolf ME, Luz B, Niehaus L, Bhogal P, Bäzner H, Henkes H (2021) Thrombocytopenia and intracranial venous sinus thrombosis after 'COVID-19 vaccine AstraZeneca' exposure. J Clin Med 10(8):1599. https://doi.org/10.3390/jcm10081599

23. Schulz JB et al (2021) COVID-19 vaccine-associated cerebral venous thrombosis in Germany. Ann Neurol. https://doi.org/10. 1002/ana.26172

24. Leask J, Kaufman J, Hughes C, Wales NS, Cashman P, Seale H (2021) The Medical Journal of Australia-Pre-print-17 May 2021 The Medical Journal of Australia-Pre-print-17 May 2021. pp $1-12$

25. D'agostino V et al (2021) Personalized medicine case report a rare case of cerebral venous thrombosis and disseminated intravascular coagulation temporally associated to the COVID-19 vaccine administration. J Pers Med 11:285

26. Bayas A, Menacher M, Christ M, Behrens L, Rank A, Naumann M (2021) Bilateral superior ophthalmic vein thrombosis, ischaemic stroke, and immune thrombocytopenia after ChAdOx $1 \mathrm{nCoV}-19$ vaccination. Lancet 397(10285):e11. https://doi.org/10.1016/ S0140-6736(21)00872-2

27. Blauenfeldt RA, Kristensen SR, Ernstsen SL, Kristensen CCH, Simonsen CZ, Hvas AM (2021) Thrombocytopenia with acute ischemic stroke and bleeding in a patient newly vaccinated with an adenoviral vector-based COVID-19 vaccine. J Thromb Haemost 19(7):1771-1775. https://doi.org/10.1111/jth.15347

28. Costentin $G$ et al (2021) Acute Ischemic stroke revealing ChAdOx 1 nCov-19 vaccine-induced immune thrombotic thrombocytopenia: impact on recanalization strategy. J Stroke
Cerebrovasc Dis 30(9):1-2. https://doi.org/10.1016/j.jstrokecer ebrovasdis.2021.105942

29. Fanni D et al (2021) Vaccine-induced severe thrombotic thrombocytopenia following COVID-19 vaccination: a report of an autoptic case and review of the literature. Eur Rev Med Pharmacol Sci 25(15):5063-5069. https://doi.org/10.26355/eurrev_202108_ 26464

30. Greinacher A, Thiele T, Warkentin TE, Weisser K, Kyrle PA, Eichinger S (2021) Thrombotic thrombocytopenia after ChAdOx1 nCov-19 vaccination. N Engl J Med 384(22):2092-2101. https:// doi.org/10.1056/nejmoa2104840

31. Guan CY, Tsai SH, Fan JS, Lin YK, Kao CC (2021) A rare case of a middle-age Asian male with cerebral venous thrombosis after COVID-19 AstraZeneca vaccination. Am J Emerg Med. https:// doi.org/10.1016/j.ajem.2021.07.011

32. Yocum A, Simon EL (2020) Thrombotic thrombocytopenic purpura after Ad26.COV2-S vaccination. Am J Emerg Med. https:// doi.org/10.1016/j.ajem.2021.05.001

33. Clark RT et al (2020) Early outcomes of bivalirudin therapy for thrombotic thrombocytopenia and cerebral venous sinus thrombosis after Ad26.COV2.S vaccination. Ann Emerg Med 78:511-514

34. Guilburd JN (2004) Case Report: thrombotic thrombocytopenia after COVID-19 Janssen vaccination. Acta Neurochir (Wien). https://doi.org/10.1007/s00701-004-0318-0

35. Haakonsen HB, Nystedt A (2021) Dyp venetrombose mer enn to uker etter vaksinering mot covid-19. Tidsskr den Nor Laegeforening 141(8):1-4. https://doi.org/10.4045/tidsskr.21.0274

36. Muster V, Gary T, Raggam RB, Wölfler A, Brodmann M (2021) Pulmonary embolism and thrombocytopenia following ChAdOx1 vaccination. Lancet 6736(21):6736. https://doi.org/10.1016/ s0140-6736(21)00871-0

37. Suresh P, Petchey W (2021) ChAdOx1 nCOV-19 vaccine-induced immune thrombotic thrombocytopenia and cerebral venous sinus thrombosis (CVST). BMJ Case Rep 14(6):4-6. https://doi.org/10. 1136/bcr-2021-243931

38. Thaler J et al (2021) Successful treatment of vaccine-induced prothrombotic immune thrombocytopenia (VIPIT). J Thromb Haemost. https://doi.org/10.1111/jth.15346

39. Tiede A et al (2021) Prothrombotic immune thrombocytopenia after COVID-19 vaccination. Blood 138(4):350-353. https://doi. org/10.1182/blood.2021011958

40. Tobaiqy M, Elkout H, MacLure K (2021) Analysis of thrombotic adverse reactions of COVID-19 AstraZeneca vaccine reported to eudravigilance database. Vaccines 9:393

41. Logunov DY et al (2021) Safety and efficacy of an rAd26 and rAd5 vector-based heterologous prime-boost COVID-19 vaccine: an interim analysis of a randomised controlled phase 3 trial in Russia. Lancet 397(10275):671-681. https://doi.org/10.1016/ S0140-6736(21)00234-8

42. Liu Y et al (2020) Association between age and clinical characteristics and outcomes of COVID-19. Eur Respir J. https://doi.org/ 10.1183/13993003.01112-2020

43. Mitchell WB et al (2021) Children and young adults hospitalized for severe COVID-19 exhibit thrombotic coagulopathy. Pediatr Blood Cancer. https://doi.org/10.1002/pbc.28975

44. Cavalcanti DD et al (2020) Cerebral venous thrombosis associated with COVID-19. Am J Neuroradiol. https://doi.org/10.3174/ AJNR.A6644

45. JCVI statement on use of the AstraZeneca COVID-19 vaccine: 7 April 2021.

46. Wei $\mathrm{C}$ et al (2020) Clinical characteristics and manifestations in older patients with COVID-19. BMC Geriatr 20(1):1-9. https:// doi.org/10.1186/s12877-020-01811-5

47. Painter EM et al (2021) Demographic characteristics of persons vaccinated during the first month of the COVID-19 vaccination program-United States, December 14, 2020-January 14, 2021. 
MMWR Morb Mortal Wkly Rep 70(5):174-177. https://doi.org/ 10.15585/mmwr.mm7005e1

48. Thompson AE, Anisimowicz Y, Miedema B, Hogg W, Wodchis WP, Aubrey-Bassler K (2016) The influence of gender and other patient characteristics on health care-seeking behaviour: A QUALICOPC study. BMC Fam Pract 17(1):1-7. https://doi.org/ 10.1186/s12875-016-0440-0

49. Greinacher A, Selleng K, Wesche J, Handtke S, Beer M, Thiele $\mathrm{T}$ Towards understanding ChAdOx1 nCov-19 vaccine-induced immune thrombotic thrombocytopenia (VITT). pp 1-13

50. Varnavski AN, Calcedo R, Bove M, Gao G, Wilson JM (2005) Evaluation of toxicity from high-dose systemic administration of recombinant adenovirus vector in vector-naïve and pre-immunized mice. Gene Ther 12(5):427-436. https://doi.org/10.1038/sj.gt. 3302347

51. Daneschvar HL, Daw H (2007) Heparin-induced thrombocytopenia (an overview). Int J Clin Pract 61(1):130-137. https://doi.org/ 10.1111/j.1742-1241.2006.00874.x

52. Lubenow N, Kempf R, Eichner A, Eichler P, Carlsson LE, Greinacher A (2002) Heparin-induced thrombocytopenia: temporal pattern of thrombocytopenia in relation to initial use or reexposure to heparin. Chest 122(1):37-42. https://doi.org/10.1378/chest.122.1. 37

53. Cuker A et al (2018) American Society of Hematology 2018 guidelines for management of venous thromboembolism: Heparin-induced thrombocytopenia. Blood Adv 2(22):3360-3392. https://doi.org/10.1182/bloodadvances.2018024489

54. Pavord $\mathrm{S}$ et al (2021) Clinical features of vaccine-induced immune thrombocytopenia and thrombosis. N Engl J Med. https://doi.org/ 10.1056/NEJMOA2109908

55. Sharifian-Dorche M, Bahmanyar M, Sharifian-Dorche A, Mohammadi P, Nomovi M, Mowla A (2021) Vaccine-induced immune thrombotic thrombocytopenia and cerebral venous sinus thrombosis post COVID-19 vaccination, a systematic review. J Neurol Sci 428:117607. https://doi.org/10.1016/J.JNS.2021. 117607

56. Warkentin TE (2006) Think of HIT. Hematol Am Soc Hematol Educ Program 46139:408-414. https://doi.org/10.1182/asheducati on-2006.1.408

57. American Heart Association/American Stroke Association Stroke Council Leadership (2021) Diagnosis and management of cerebral venous sinus thrombosis with vaccine-induced thrombotic thrombocytopenia. Stroke. https://doi.org/10.1161/STROKEAHA.121. 035564

58. Karnam A, Lacroix-Desmazes S, Kaveri SV, Bayry J (2021) Vaccine-induced prothrombotic immune thrombocytopenia (VIPIT): consider IVIG batch in the treatment. J Thromb Haemost. https:// doi.org/10.1111/jth. 15361

59. Uzun $\mathrm{G}$ et al (2021) The use of IV immunoglobulin in the treatment of vaccine-induced immune thrombotic thrombocytopenia. Blood 138(11):992. https://doi.org/10.1182/BLOOD.2021012479

60. Cines DB, Bussel JB (2021) SARS-CoV-2 vaccine-induced immune thrombotic thrombocytopenia. N Engl J Med 384(23):2254-2256. https://doi.org/10.1056/NEJME2106315

61. Souaid R, Lu C (2018) Incidental steroid use may worsen outcomes in patients with heparin induced thrombocytopenia in the ICU setting [abstract]. Arthritis Rheumatol. 70(suppl 10):111

62. M. James B. Bussel, MD; Jean M. Connors, MD; Douglas B. Cines, MD; Cynthia E. Dunbar, MD; Laura C. Michaelis, MD; Lisa Baumann Kreuziger, MD; Agnes Y. Y. Lee, MD, MSc; and Ingrid Pabinger-Fasching, "Thrombosis with Thrombocytopenia Syndrome (also termed Vaccine-induced Thrombotic Thrombocytopenia) Version 1.4,” 2021

Publisher's Note Springer Nature remains neutral with regard to jurisdictional claims in published maps and institutional affiliations. 